\title{
MECANISMOS DE INFORMACIÓN SOBRE LAS RUTAS DE PROTECCIÓN A LOS PACIENTES EN CASO DE FALLA DEL SERVICIO: ESTUDIO DE CASO HOSPITAL UNIVERSITARIO DE SINCELEJO, AÑO 2017
}

\author{
Pedro Juan González Ortiz ${ }^{1}$ \\ Pedro Luis González Gómez² \\ Wilson Alonso Montoya Gaviria ${ }^{3}$
}

\section{Resumen}

La sistemática y creciente vulneración de los derechos de los pacientes por parte de las E.P.S. y de las Instituciones Prestadoras de Servicios de Salud, y en el mismo nivel las circunstancias de los errores médicos y como consecuencia la violación a la Lex Artis, nos motivaron a indagar sobre la importancia para el paciente de informarse y conocer de primera mano sus derechos y mecanismos de protección. En igual forma, las rutas a seguir cuando se trata de la defensa de los mismos en los casos de falla en el servicio de salud derivados de cualquier causa. Esto porque el paciente es considerado víctima y existe la previsión legal de acceder a la justicia en busca de materializar los derechos en las rutas de las que trata esta investigación: información, verdad, justicia y reparación integral por los daños generados por el citado prestador o responsable de los perjuicios suscitados por la falla y de esta manera hacer efectivas las garantías que el Estado pone a su disposición.

Palabras Clave: derechos de los pacientes, derechos humanos, lex artis, mecanismos de información, rutas de protección, derecho médico, falla del servicio.

$1 \quad$ Egresado del Programa de Derecho de la Corporación Universitaria del Caribe CECAR. Email: pedro.gonzalezo@cecar.edu.co

2 Egresado del Programa de Derecho de la Corporación Universitaria del Caribe CECAR. Email: pedro.gonzalezg@cecar.edu.co

3 Egresado del Programa de Derecho de la Corporación Universitaria del Caribe CECAR. Email: Wilson.montoya@cecar.edu.co 


\section{Abstract}

The systematic and growing violation of patients' rights by the E.P.S. and the Healthcare Provider Institutions, and at the same level the circumstances of the medical errors and as a consequence, the violation of the Lex Artis, motivated us to inquire about the importance for the patient of being informed and to know first-hand their rights and protection mechanisms. In the same way, the routes to follow when it comes to the defense of the same in cases of failure in the health service derived from any cause. This is because the patient is considered a victim and there is a legal provision to access justice in order to materialize the rights in the routes covered by this investigation: information, truth, justice and integral reparation for the damages generated by the aforementioned provider or responsible for the damages caused by the failure and in this way make effective the guarantees that the State puts at your disposal.

Keywords: rights of the patients, human rights, lex artis, mechanisms of information, medical right, protection router fails in the service.

\section{Introducción}

Este trabajo tiene como objetivo dar a conocer los resultados de una investigación socio-jurídica realizada para establecer la eficacia de los mecanismos de información sobre las rutas de protección de los pacientes víctimas de fallas en la prestación del servicio médico en el Hospital Universitario de Sincelejo en el periodo 2014-2017. En el desarrollo de la presente investigación se describen las dificultades que libra el usuario del servicio médico frente a hechos y consecuencias del servicio de salud, toda vez que el desconocimiento por falta de información al paciente, responsabilidad de las entidades que integran el sistema general de seguridad social en salud, evidencia su inexistencia en materia de responsabilidad médica y el derecho médico. El tema en referencia se estudió desde diferentes aristas, con el objetivo de darle prevalencia al derecho que asiste al paciente como víctima de una falla en el servicio, así como mostrar algunos mecanismos de información sobre las rutas de protección al paciente cuando se presentan errores médicos. De esta manera se pretende crear conciencia en el paciente e interesar a las EPS, IPS y entidades responsables de la urgencia de implementar estas medidas para buscar la máxima garantía y calidad en los servicios de salud. 
Factores como la corrupción generalizada, la desorganización administrativa, la competencia desleal entre sus actores, la fuerte intervención de algunas agencias del Estado en favor del sector privado en detrimento del sector público, el cierre generalizado de hospitales, las huelgas continuas de los trabajadores del sector, al igual que el rechazo de la racionalidad administrativa y económica del sistema hacen del sector salud un frente del estado carente de seguridad y credibilidad. Además las múltiples y diferentes fallas en la prestación del servicio médico por parte de los actores a causa de la negligencia, impericia, imprudencia e inobservancia de protocolos y reglamentos, como una realidad en ascenso, configuran un panorama asaz desalentador en relación con la tarea que tiene el Estado a nivel nacional, regional y local de garantizar la prestación del servicio de salud como derecho, las rutas de información y los mecanismos de protección de estos, a través de las distintas acciones y medios de control instituidos para ello.

Desde lo constitucional, normativo, y en el ámbito internacional de los derechos humanos se precisa la existencia de los mecanismos de protección de los derechos del paciente. El hallazgo de estadísticas en aumento en el que las instituciones de salud y el cuerpo médico han incurrido en fallas en el servicio de salud permiten inferir la reincidencia en la vulneración de ese marco normativo. Según investigaciones del Centro de Estudios en Derecho y Salud Cendes, de la Facultad de Derecho CES, ( 2015 )se encontraron novecientos sesenta y cuatro archivos con solicitudes de dictámenes periciales durante el período de estudio (2014 - 2017), los cuales comprenden demandas ya instauradas y solicitudes de conceptos médicos, evidenciando que al pasar de los años se han aumentado. Estos datos condujeron a la reflexión sobre un planteamiento propositivo sustentado en la investigación que en materia del derecho médico ilustra y defiende los derechos del paciente en los casos en que el arte médico incumple el deber de informar amplia y expresamente los riesgos médicos en los que se puede encontrar un paciente. A este respecto, las empresas prestadoras como entidades aseguradoras y contratantes del servicio no garantizan un sistema de información personalizada o tecnológica que contextualice al paciente víctima de la culpa médica o falla del servicio, para que éste utilice las rutas y los mecanismos de protección que todo el ordenamiento jurídico colombiano e internacional coloca a su disposición. (Cendes, Univ. CES 2014). 
Es por ello que el análisis de las rutas de información y los mecanismos de protección de los derechos de los pacientes, así como su ineficacia (Fernández Mónica, 2014) inciden en la puesta en acción regulatoria y jurídica cuando se trata de fallas en la prestación del servicio de salud, lo cual configura para esta investigación el factor más importante con miras a la garantía del derecho. La necesidad de promover y aplicar mecanismos para el restablecimiento de derechos en el contexto de la salud se hace una realidad imperiosa. Uno de los aspectos a destacar dentro del ámbito del bioderecho es la protección a la vida y la salud de las personas, la cual está recogida en diversos instrumentos internacionales; allí se observa la protección en situaciones muy específicas, como el caso de la previsión normativa ante los tratos inhumanos y degradantes. Esto limita y condiciona la atención a otras incidencias que pueden presentarse dentro de estos mismos derechos como son los de la errónea práctica médica; en este caso es necesario la ampliación de la protección jurídica. En ese sentido, se considera imprescindible disponer de mecanismos de información que puedan considerar el riesgo manifiesto al cual se exponen las víctimas de un mal servicio médico que, bien por acción u omisión, pudiera ocasionar una lesión a la vida o a la salud, limitando su derecho a estos, y a la integridad psíquica, física y moral. Por lo tanto lo establecido en la preceptiva tácitamente, a la luz de los derechos de los pacientes, debe estar expreso dentro de los Derechos Humanos, tal como lo cita (Bastidas, N. 2012).

A este respecto, alrededor del ejercicio de las actividades de salud, se generan unas consecuencias que pueden afectar jurídicamente al profesional de la salud, originadas por el daño causado al paciente. Es por ello y en relación con el vínculo contractual y a la seguridad del paciente, la obligación de la institución y el personal médico considerarla más allá de medio, como una autentica obligación de resultado a fin de asegurar la calidad en la prestación de servicios médicos sanitarios a todos los usuarios. Igualmente se ocasiona un desequilibrio en el patrimonio de las víctimas o sus familiares, porque tienen que cubrir con su propio patrimonio los daños y perjuicios producidos por la falla del servicio, el error médico, una negligencia, o por una imprudencia. La victima directa o perjudicado por reflejo, entendido también como los denominados indirectos causahabientes (familiares) y no causahabientes del daño médico-sanitario producido por el prestador de salud, cuenta con la capacidad de demandar la protección de sus derechos a través de las acciones legales consagradas en nuestro ordenamiento jurídico 
colombiano. Son medios procesales que aseguran la protección judicial de los derechos e intereses de los pacientes, que pueden resultar afectados o, en su defecto, amenazados por las empresas promotoras o prestadoras de los servicios en salud pública o privada.

Falla del servicio con ocasión de la inadecuada prestación de servicios de salud

A este respecto y al tenor de la Ley 472/98 de evitar el daño contingente, hacer cesar el peligro, la amenaza, la vulneración o restituir las cosas a su estado anterior. En este orden de ideas, el objetivo de la información es salvaguardar los derechos e intereses colectivos, en este caso de los pacientes, de todas las actividades que puedan ocasionar daños generadores de perjuicios, por la inadecuada prestación de servicios. Así las cosas, jurídicamente es el estado el ente responsable y llamado a poner en ejecución el sistema de protección de los derechos humanos del paciente, signado por los estados en convenciones internacionales y su incumplimiento genera responsabilidad. La Corte Constitucional ha precisado que esta ruta de los derechos se caracteriza por ser derechos de solidaridad, participativos y no excluyentes, en cuanto no constituyen un sistema cerrado a la evolución social y política, que pertenecen a todos y a cada uno de los individuos, por lo que esta información exige una labor anticipada de protección y una acción pronta de la justicia, dirigida a impedir su afectación y en su defecto a lograr su inmediato restablecimiento (López, J. 2014)

El objetivo de estas acciones judiciales previamente informadas al paciente, como rutas de protección, tiene unos propósitos preventivos, suspensivos y restaurativos. Específicamente, en correspondencia con nuestro interés, las instituciones de salud del Departamento de Sucre no están exentas de las dificultades anteriormente descritas, sobre todo las relacionadas con las fallas en la prestación del servicio médico. "Indudablemente el error es perfectamente lógico en cualquier actividad humana y la medicina no está excluida de éste, no es infalible. No obstante, el derecho a equivocarse es también una responsabilidad que asume el individuo" (Ruiz w, 2004). Si bien es cierto que los errores no justifican el actuar médico, tampoco es menos cierto que las entidades de salud deban asumir su responsabilidad social, primando para ellas sus valores y principios corporativos frente a la sociedad, transformando en servicios de calidad lo que toman de ella para el desarrollo de su actividad. 
Descrito el planteamiento y enunciada la justificación de la investigación, se realiza el abordaje de algunos antecedentes históricos que hacen referencia a la responsabilidad médica inexistente y además las acciones jurídicas a la que se sometían los médicos y los actores de la salud cuando se generaba un daño por la defectuosa praxis médica. Al inicio de la humanidad, la responsabilidad medica no existía y el medico tenía (Ruiz w, 2004), un carácter sagrado que podía ir más allá de cualquier pena o sanción. Sin embargo esta penalización se inició con las acciones que realizo Hamurabi, Rey de Babilonia al penalizar a los médicos imperitos y negligentes y la Lex Aquila Romana, que reguló el resarcimiento del daño causado a otro.

Hoy por hoy, el médico es un profesional más, que ejerce su profesión y puede ser acusado ante los jueces correspondientes. Según Yepes (2008) en Colombia siempre han existido normas jurídicas que permiten plantear la existencia de diferentes clases de responsabilidad por la prestación de servicios de salud, los cuales se mencionarán en esta investigación. En este orden de ideas, ubicando el estudio en el sistema jurídico y de salud actual en la línea de investigación socio jurídica tratada, se ha enfatizado en los contextos y matices relevantes en los que se ve inmerso el servicio de salud, el actuar médico, los derechos del paciente y las acciones jurídicas en las rutas protectoras y garantes en un Estado democrático y social de Derecho:

Además de la responsabilidad personal que pueda surgir para el personal médico y paramédico, existe una diversidad de disposiciones de carácter administrativo, asistencial y jurídico de obligatorio cumplimiento por las entidades promotoras e instituciones prestadoras de servicios de salud que pueden originar investigaciones e intervenciones por parte de las direcciones seccionales y locales de salud y de la Superintendencia Nacional de Salud (Yepes, S. 2008)

En efecto, en el ámbito internacional existe una normativa que aborda la protección de los Derechos Humanos, cual es la Resolución 56/83 de la Asamblea General de las Naciones Unidas que establece que los Estados partes de la Convención Americana de Derechos Humanos son internacionalmente responsables por las acciones $u$ omisiones que configuren desprotección y violación de los Derechos Humanos. Por lo tanto la falta de regulación total o parcial de sistemas de protección del derecho a la vida y la salud en los asuntos de falla médica, son omisiones normativas que configuran responsabilidad estatal. 
La Organización Mundial de la Salud, OMS, ha reafirmado permanentemente que la salud es uno de los derechos fundamentales de todo ser humano, el cual incluye una atención sanitaria oportuna, asequible y de una calidad enteramente satisfactoria. Dicha responsabilidad es propia de los Estados, quienes constitucionalmente deben gestar las condiciones necesarias para que las personas puedan vivir de manera saludable. Asimismo es tarea estatal el impulso y el ofrecimiento de servicios de salud con disponibilidad, accesibilidad, aceptabilidad y calidad garantizadas (Matera, J. 2018). La OMS plantea que el derecho a la salud abarca cuatro elementos básicos:

- Disponibilidad: se debe contar con un número suficiente de establecimientos, bienes y servicios públicos de salud, así como de 'programas que propendan por la prestación de un excelente servicio.

- Accesibilidad: los establecimientos, los bienes y los servicios de salud deben ser accesibles a todos en general

- Aceptabilidad: todos los establecimientos, los bienes y servicios de salud deberán ser respetuosos de la ética médica y culturalmente sensibles a los requisitos del género humano y al ciclo de vida.

- Calidad: los establecimientos, los bienes y los servicios de salud deberán ser apropiados desde el punto de vista científico y médico, y ser de buena calidad".

Según López, (López, J.2014) El usuario del servicio médico puede sufrir una lesión de carácter temporal o permanente, debido a la acción u omisión del prestador sanitario. El perjuicio al paciente infringe las normas, reglas y principios contenidos en la Constitución Política de Colombia y demás normas legales que requieren de un sistema procesal para hacer efectivos los derechos del paciente víctima del daño. No obstante, la acción u omisión productora del daño, puede enfrentarse por medio de instrumentos constitucionales: la acción de tutela, popular y de grupo, como también los medios de control del contencioso administrativo formando parte de este tipo de mecanismos. Al realizar una aproximación teórica a la figura de la falla del servicio con ocasión de la inadecuada prestación de servicios de salud e identificar las más comunes en el servicio, y en atención a los pronunciamientos del Consejo de Estado, se deben tener 
claros algunos conceptos relevantes, a saber: a) Concepto de falla en el servicio, b) responsabilidad por falla en el servicio médico.

\section{Falla en el servicio}

El primero, según el módulo la falla en el servicio, editado por la Universidad Nacional Autónoma y a Distancia en adelante UNAD (s.f.):

La falla en el servicio se desprende de la prestación de un servicio estatal, que al no ser prestado en la forma debida genera un daño, derivándose que el Estado tenga que responder directamente por ese daño, lo cual se configura como nexo causal. Este concepto tiene como complemento en este estudio el de la responsabilidad médica, dado que la prestación del servicio de salud está a cargo del Estado, quien por lo tanto es el garante de la misma y al no poder ejercer su control completamente genera la falla en el servicio médico; así se explica el concepto de la responsabilidad por falla en el servicio.

El segundo hace referencia a la responsabilidad médica que supone la obligación de los médicos de dar cuenta ante la sociedad por los actos realizados en la práctica profesional, cuya naturaleza y resultados sean contrarios a sus deberes, por incumplimiento de los medios y/o cuidados adecuados en la asistencia del paciente; pudiendo adquirir, a veces, relevancia jurídica. Según Torres, L. (2016) la responsabilidad médica significa la obligación que tiene el médico de reparar y satisfacer las consecuencias de sus actos, omisiones y errores voluntarios o involuntarios, dentro de ciertos límites y cometidos en el ejercicio de su profesión; sin embargo, el médico puede cometer errores, los mismos que no serán reprochables ética y legalmente, si ha tratado al paciente con los medios adecuados, con los conocimientos actuales y siguiendo las normas que su deber le imponen.

La Ley 23 de 1981 es la principal fuente normativa en lo atinente a la ética médica en Colombia versus pacientes. Como lo expresa la citada Ley 23 de 1981 en su Título I, Capitulo 1, Artículo 4:

La relación médico paciente es el elemento primordial en la práctica médica. Para que dicha relación tenga pleno éxito, debe fundarse en un compromiso responsable leal y autentico... De acuerdo con dicha ley la relación médico paciente se cumple en los siguientes casos: Por decisión voluntaria y espontanea de ambas partes, por acción 
unilateral del médico en un caso de emergencia, por solicitud de terceras personas, por haber adquirido el compromiso de atender a personas que están a cargo de una entidad privada o pública.

Título II, Capitulo 1, Articulo 5. La ley 23 de 1981 ya lo había tratado en el título III, capítulo 3, artículo 34: La historia clínica es el registro obligatorio de las condiciones de salud del paciente. Es un documento privado, sometido a reserva, que únicamente puede ser conocido por los terceros previa autorización del paciente o en los casos previstos por la ley.

En Colombia, el derecho a la salud aparece por primera vez consagrado a nivel constitucional en el año 1936, incorporándose como un elemento trascendental el derecho a la asistencia pública. De acuerdo con esto, la Constitución reconoció el derecho a la salud con un carácter dual: por una parte, como un derecho individual fundamental en sí mismo, y por otra como derecho fundamental conexo a la vida. A partir de este momento en nuestro país se inicia un proceso en pro de la garantía del derecho a la salud en los ciudadanos, proceso que se fortaleció y se ha ido consolidando en las últimas tres décadas, particularmente con la Constitución de 1991.

En este aspecto, desde la Constitución de 1991 se empieza a vislumbrar la salud como un componente dentro de un Sistema de Seguridad Social Integral con la intención de responder de manera mucho más eficaz y pertinente a las recomendaciones Internacionales. Entre el catálogo de derechos que protege la Constitución de 1991, en pro de los Derechos Económicos, Sociales y Culturales tenemos: El derecho a la salud y la seguridad social (art. 44); el derecho irrenunciable a la seguridad social (art 48); y el derecho a la salud y el saneamiento ambiental (art 49). Es claro que desde la Carta Política de 1991, Colombia es un país que cuenta con los mecanismos para garantizar el derecho a la salud de una forma responsable en concordancia con los elementos básicos que plantea la OMS.

Además de los principios citados, el de la calidad se refiere al establecimiento de controles para garantizar a los pacientes la atención oportuna, integral, continua y según estándares de la práctica médica. Es importante tener en cuenta que mediante el Decreto 1011 del 2006, del Ministerio de Protección Social, se reglamentó el sistema obligatorio de la garantía de calidad de la atención en salud del sistema general de seguridad social, aplicable a los prestadores de servicios, entidades 
promotoras, empresas de medicina prepagada y demás entidades territoriales de salud. La Ley 100 de 1993, reformada por la Ley 1122 de 2007, regula el sistema general de seguridad social, no solo en salud sino también en pensiones y riesgos profesionales, con una reglamentación extensa, lo cual nos exige limitarnos a referenciar las disposiciones legales que tienen relación con la responsabilidad médica. Nuestra Constitución consagra en Colombia el reconocimiento a la personalidad jurídica, la intimidad, la libertad de conciencia, la protección de la mujer, el niño y el anciano, así como a los débiles físicos y psíquicos; regula el derecho al saneamiento ambiental y a la seguridad social. Existen diversos códigos y leyes en materia de derecho de personas y de filiación, tipos penales que tutelan bienes jurídicos relacionados con la salud, la integralidad y la intimidad, normas administrativas relacionadas con el sistema general de seguridad social en salud, pensiones y riesgos profesionales, así como diversas leyes que regulan aspectos puntuales del derecho médico.

El artículo 49 de la Constitución Política de Colombia, modificado por el Acto Legislativo 02 de 2009, prevé: La atención de la salud y el saneamiento ambiental son servicios públicos a cargo del estado. Se garantiza a todas las personas el acceso a los servicios de promoción, protección y recuperación de la salud. Corresponde al Estado organizar, dirigir y reglamentar la prestación de servicios de salud a los habitantes y de saneamiento ambiental conforme a los principios de eficiencia, universalidad y solidaridad. También establecer las políticas para la prestación de servicios de salud por entidades privadas, y ejercer su vigilancia y control. Así mismo, establecer las competencias de la Nación, las entidades territoriales y los particulares, y determinar los aportes a su cargo en los términos y condiciones señalados en la ley.

Asimismo la ley señala que los servicios de salud se organizarán en forma descentralizada, por niveles de atención y con participación de la comunidad. En tal sentido, el Estado debe contar con políticas públicas de salud que garanticen un efectivo acceso de la población al servicio de salud, basado en un óptimo servicio de alta calidad y que asuma la atención del paciente con excelente grado de responsabilidad, por lo que requiere un cuerpo médico altamente capacitado y así disminuir los daños antijurídicos que se generan cuando se presentan dificultades en la atención.

En nuestro país, la Ley Estatutaria 1751 de 2015 reguló el derecho fundamental a la salud, el cual durante mucho tiempo fue desarrollado por la jurisprudencia constitucional, inicialmente como derecho fundamental 
por conexidad con la vida, siendo posteriormente elevado al rango de derecho fundamental, en posición adoptada por la Corte Constitucional en la sentencia T-589 de 2003. El novedoso marco regulatorio confirmó el derecho a la salud como fundamental, determinando que es autónomo e irrenunciable en lo individual y en lo colectivo y que el mismo cobija el acceso a los servicios de salud de manera oportuna, eficaz y con calidad para la preservación, el mejoramiento y la promoción de la salud. Igualmente se determinó que la prestación del servicio público de salud es esencial y obligatoria y su dirección, supervisión, organización, regulación, coordinación y control están en cabeza del Estado, para lo cual deberá entre otras acciones:

a. Abstenerse de afectar directa o indirectamente el disfrute del derecho fundamental a la salud, de adoptar decisiones que lleven al deterioro de la salud de la población y de realizar cualquier acción u omisión que pueda resultar en un daño en la salud de las personas.

b. Formular y adoptar políticas de salud dirigidas a garantizar el goce efectivo del derecho en igualdad de trato y oportunidades para toda la población, asegurando para ello la coordinación armónica de las acciones de todos los agentes del Sistema.

c. Establecer mecanismos para evitar la violación del derecho fundamental a la salud y determinar su régimen sancionatorio.

d. Velar por el cumplimiento de los principios del derecho fundamental a la salud en todo el territorio nacional, según las necesidades de salud de la población.

En virtud de los principios constitucionales y normativos anteriormente tratados, es imprescindible hacer referencia a lo que en materia jurídica deviene de lo social en cuanto al derecho a la salud, y principalmente amparando lo concerniente al actuar médico y su relación con el paciente, cuando se presentan casos donde la responsabilidad medica aflora. Así, se hace alusión a los diferentes puntos de vista de algunos autores en materia de derecho médico:

Yepes, S. (2008) cita en referencia y expresa: Para Aguilar (1996) el derecho médico es el conjunto de normas jurídicas y preceptos éticos, morales, de carácter público y privado que regulan la actividad del médico con motivo del ejercicio de su profesión, la relación jurídico médico paciente y las consecuencias derivadas de la misma, estableciendo así los principios generales de la responsabilidad médica. Según Giglio 
(1996) el derecho médico es una rama autónoma del derecho que regula la actividad del médico, en su ejercicio profesional la relación médico paciente y las consecuencias derivadas de esta. Romero (1996) señala que el derecho médico es la parte del ordenamiento jurídico referida al ejercicio de la profesión médica y, por asimilación, de otras profesiones sanitarias o no vinculadas directamente con la salud. De otro lado Varsi (1996) enseña que el derecho medico es una nueva forma de estudiar jurídicamente las consecuencias del desarrollo, aplicación y practica de las ciencias de la salud en el ser humano. Así mismo, Rodríguez (1998) indica que el derecho medico es la rama del derecho que estudia las relaciones de los profesionales de la salud (médicos y no médicos) entre sí, con los usuarios de los servicios sanitarios (públicos y privados), con el sistema de salud y, de un modo más general, las relaciones entre las ciencias de la salud y la sociedad. En opinión del jurista Obando (2016) el derecho medico está conformado por todas las normas jurídicas que regulan las actividad sanitaria, son todas las disposiciones legales que otorgan garantías a la relación médico-paciente para la protección de los derechos fundamentales tanto del paciente como del médico.

Responsabilidad Civil: De acuerdo a Yepes, (Yepes, S.2008) resulta de gran utilidad mencionar algunos aspectos generales de la responsabilidad patrimonial por la prestación de servicios de salud, como la indemnización de los perjuicios ocasionados a un paciente o a sus familiares en la prestación de un servicio de salud que ha afectado su salud, vida o integridad personal. A diferencia de las demás clases de responsabilidad, cuyo ámbito pasivo es más reducido en materia de responsabilidad civil, la acción puede dirigirse tanto a personas naturales, ya sean o no profesionales, como contra personas jurídicas, trátese de entidades promotoras de salud, administradoras del régimen subsidiado, cooperativas, sociedades e instituciones prestadoras de servicios de salud, como farmacias, laboratorios farmacéuticos, clínicos o patológicos, bancos de sangre y cualquiera otra entidad que preste servicios de salud. Finalmente, y teniendo en cuenta que existe una jurisdicción ordinaria, si la persona natural o jurídica tiene naturaleza civil, los jueces competentes serán los jueces civiles.

Responsabilidad Contenciosa Administrativa: Cuando el servicio de salud es prestado por un hospital o un funcionario público, la competencia pertenece al juez administrativo, lo cual sucede igualmente por fuero de atracción. La acción se denomina de reparación directa, y tiene un término de caducidad de dos años, a diferencia de la demanda de responsabilidad civil, que prescribe en diez años. Aunque tiene una denominación distinta, 
constituye igualmente una demanda del paciente o sus familiares por la prestación defectuosa de un servicio de salud y que se denomina falla o falta en el servicio público hospitalario. De conformidad con el artículo 90 de la Constitución Nacional, el Estado debe responder por el daño antijurídico causado por la acción o la omisión de las autoridades públicas y en los eventos de culpa grave del funcionario público, el Estado puede repetir en su contra. Mediante la Ley 678 de 2001 se reglamentó la repetición y el llamamiento en garantía indicando que es deber de las entidades ejercitar el llamamiento en garantía cuando el "daño causado ha sido consecuencia de la conducta dolosa o gravemente culposa de sus agentes", y en su artículo 19 señala que podrá solicitar "el llamamiento en garantía del agente frente al que aparezca prueba sumaria de su responsabilidad al haber actuado con dolo o culpa graves.

Responsabilidad Penal: La responsabilidad penal por el ejercicio de la medicina ha venido ocupando un papel esencial en las acciones legales de los profesionales de la salud y ha sido objeto de numerosos escritos en los ámbitos internacional y nacional. El Código Penal Colombiano sanciona con penas una serie de conductas que afectan a los valores más altos que exigen protección de la sociedad y que se denominan bienes jurídicos. Finalmente la doctrina ha señalado que puede surgir responsabilidad penal por la negación de servicios médicos bajo la modalidad de delitos culposos o por omisión.

Responsabilidad Disciplinaria: En aquellos casos en los cuales el profesional de la salud tiene el carácter de funcionario público, ciertas conductas pueden dar lugar a la realización de un proceso disciplinario por parte de la dependencia interna de la institución o de la Procuraduría General de la Nación. La Ley 734 de 2002 y los mismos regímenes disciplinarios internos deben definir las acciones $u$ omisiones objeto de sanción y efectuarse igualmente un proceso con plenas garantías tanto en la etapa instructiva como en la formulación de cargos, practica de pruebas e interposición de recursos. Las sanciones consisten, entre otras, en multas, suspensión y destitución. Igualmente pueden tener consecuencias prácticas para otros procesos judiciales contra el profesional.

Responsabilidad Estatutaria o Laboral: Se incluye este tipo de responsabilidad habida cuenta de la existencia de reglamentos en cooperativas, empresas, sociedades científicas, entidades promotoras de salud e instituciones prestadoras de servicios de salud de carácter privado, que regulan en un determinado momento deberes de los profesionales, así como sanciones de diversa índole, resultado esencial de la implementación 
de procedimientos con las correspondientes garantías al debido proceso y el derecho a la defensa.

Obligación de Medio: El régimen tradicional de la culpa probada o responsabilidad subjetiva indica que corresponde al paciente demostrar la culpa del profesional de la salud o de la institución que le presto el servicio para que surja la responsabilidad. Dicho sistema fue implantado al tiempo que se señaló que la responsabilidad medica era de carácter contractual, en una sentencia conocida como el fallo "Mercier", dictado en Francia en 1936, en el cual se señaló que el profesional de la salud no se obliga a curar al paciente sino a "...brindarle los cuidados, no cualesquiera, pero concienzudos, atentos y, reserva hecha de circunstancias excepcionales, conforme a los datos adquiridos de la ciencia" (Yepes, s. 2008) La misma jurisprudencia comenzó a decantar el concepto de datos adquiridos de la ciencia y en algunos fallos utiliza el término de datos actuales. El fallo "Mercier" se ha constituido en uno de los aportes jurisprudenciales más importantes. Mereció una mención años más adelante y todavía se constituye en referencia obligada en la mayoría de los procesos de responsabilidad civil contra un profesional de la salud. Teniendo en cuenta que la obligación del profesional de la salud es de medio, debe entonces el paciente demostrar la culpa de aquel, y puede el medico exonerarse de la responsabilidad que se le imputa, si acredita que actuó con diligencia y cuidado, esto es, con ausencia de culpa, o si demuestra que existió caso fortuito, hecho de un tercero o culpa exclusiva del paciente.

Obligación de Resultado: Por oposición a la obligación de medio, propia de la responsabilidad subjetiva, se encuentra la obligación de resultado, aplicable por algún sector de la doctrina a la cirugía y a la medicina estéticas, reconocida por la jurisprudencia en aquellos casos en los cuales el profesional utiliza terminología asegurando resultados. Según la Corte... Es por ello que en la prestación de servicios de salud debe utilizarse un lenguaje prudente por el profesional y una publicidad y oferta de servicios acorde con la naturaleza de la actividad, para no agravar la obligación del prestador".

Falla del Servicio Médico y Hospitalario: El régimen de responsabilidad de la falla o falta del servicio aplicable en materia contencioso administrativa tuvo, con algunas variantes, gran aplicación hasta 1992 , cuando se consagró la presunción de falla. Lo importante de la teoría era el carácter anónimo de la falta que permitía deducir la responsabilidad del servicio médico y hospitalario, tanto en Francia como en Colombia". 
La Lex Artis Ad Hoc: La locución latina Lex Artis, literalmente "Ley del Arte" o regla de la técnica de actuación de la profesión de la cual se trata, ha sido empleada para referirse a un cierto sentido de apreciación sobre si la tarea ejecutada por un profesional es o no correcta o se ajusta o no a lo que debe hacerse; en definitiva, si corresponde con la actuación de un buen profesional, un buen técnico o un buen artesano. Es decir, se intenta calificar si la actuación del profesional se ajusta al concepto de excelencia en el momento en que juzga dicha actuación. La Lex Artis se aplica para la medición de la obra o el resultado obtenido por un profesional. Es criterio valorativo de la corrección del concreto acto médico ejecutado por el profesional de la medicina que tiene en cuenta las especiales características de su autor, de la profesión, de la complejidad y trascendencia vital del acto y, en caso de la influencia de otros factores endógenos, para calificar dicho acto de conforme o no con la técnica normal requerida derivando de ello tanto el acervo de exigencia o requisitos de legitimación a actuación licita, de la correspondiente eficacia de los servicios prestados y, en particular, de la posible responsabilidad de su autor medico por el resultado de su intervención o acto médico ejecutado...

Impericia: Se define como la falta de pericia o habilidad en una ciencia o arte. Aplicado al campo de los servicios de salud, consiste en la falta de conocimientos o capacidad profesional para realizar un acto médico. Sobre esta modalidad de culpa, la jurisprudencia ha dicho que "...la impericia médica es la falta- total o parcial- de pericia, entendiendo por esta la sabiduría, conocimientos técnicos, experiencia y habilidad en el ejercicio de la medicina". Al médico general que efectúa un procedimiento de gran complejidad, como una neurocirugía, y comete un error por desconocimiento o inexperiencia se le catalogaría como imperito".

Imprudencia: Consiste en la falta de templanza, cautela, prudencia y buen juicio. Existe cuando se somete a un paciente a un riesgo injustificado que no corresponda a sus condiciones clínico-patológicas. Según la jurisprudencia, "... la imprudencia es la falta de prudencia; realizar un acto con ligereza, sin las adecuadas precauciones, la prudencia debe ser una de las virtudes médicas, pues es esencial que el medico ejerza su profesión con cordura, moderación, cautela, discreción y cuidado". Se presentaría cuando el médico, sin contar con el instrumental, los elementos médicos o la infraestructura adecuadas, efectúa un procedimiento sin poder manejar acertadamente una complicación. No habría responsabilidad cuando el medico buscando preservar la vida o la integridad de un paciente, trata de ayudarlo sin contar con los medios disponibles en un evento de urgencia". 
Negligencia: Es un descuido, o falta de cuidado, o una omisión, como cuando no se emplean medios conocidos y disponibles en la prestación de un servicio de salud. Si el profesional no acatando medidas de cuidado, higiene o seguridad que tiene a su disposición, atenta contra la salud del paciente, estaría actuando de manera negligente. Igualmente, si el profesional no revisa la historia clínica, las instrucciones de un equipo, las indicaciones de otro colega, las contraindicaciones de un tratamiento, la anormalidad evidente del instrumental o la fecha de vencimiento de unos medicamentos".

Violación de Reglamentos: Está constituido por la infracción de los principios científicos y las normas legales. Además de ello, en el campo médico, se daría cuando el profesional se aparta de la lex artis, en la realización de una técnica o un procedimiento. Comprendería además la violación de normas legales que consagran reglas precisas y de obligatorio cumplimiento, así como normas de ética médica, estudios profesionales y escuelas científicas. Se plantean asimismo discusiones sobre los protocolos institucionales y la ciencia basada en la evidencia, para lo cual retoma importancia el principio de la libertad terapéutica con sustento científico y precedido de consentimiento informado. En lo que tiene que ver con la lex artis o lex ad hoc, vale la pena hacer alusión a los pronunciamientos del Tribunal Supremo Español. El primer antecedente legal de la responsabilidad médica en Colombia se inició con la Ley 67 de 1935, la cual consagra que la medicina constituye una función social y que tanto el medico como los demás profesionales eran responsables civil y penalmente por sus omisiones en el ejercicio profesional. Esta ley también limita el ejercicio de la homeopatía y establece sanciones para el ejercicio inadecuado de la profesión médica (Restrepo, N. 2015)

\section{Desarrollo de la Normativa de la Responsabilidad Médica}

- Ley 42 de 1945: Dispone la creación de la Escuela Superior de Asuntos Medico- legales.

- Ley 9 de 1952: Establece el año rural y se le asignan funciones médico-legales a los médicos rurales.

- Código de moral medica: Aprobado en 1953 por la Asociación de médicos católicos colombianos.

- Ley 14 de 1962: Dicta normas relativas al ejercicio de la medicina.

- Ley 9 de 1979: Código sanitario nacional. 
- Ley 23 de 1981: Código de ética médica y sus derechos reglamentarios.

- Ley 73 de 1988: Establece normas sobre el trasplante de órganos.

- Ley 10 de 1990: Reorganiza el sistema nacional de salud.

- Ley 6 de 1991: Reglamenta la anestesiología.

- Resolución 8430 de 1993: Establece formalidades para el desarrollo de investigaciones, el debido cuidado, consentimiento informado, investigación en sujetos humanos, tratamiento de animales en investigación y otros.

- Ley 100 de 1993: Crea el Sistema de Seguridad Social Integral.

- Decreto 1022 de 2006: Crea el Sistema Obligatorio de Garantía de Calidad, SOGCS

- Ley 1122 de 2007: Establece las políticas para la prestación de servicios de salud

- Resolución 1441 de 2013: Establece las condiciones de habilitación para prestadores de salud.

- Ley 1751 de 2015 SOGC: Establece derechos y deberes de las personas en relación con el derecho fundamental a la salud.

- Ley 1400 y 2019 de 1970. Código de Procedimiento Civil.

- Ley 1564 de 2012.Código General del Proceso.

\section{Derechos y mecanismos de información de los pacientes en la falla del servicio}

Estos derechos y mecanismos de información de los pacientes forman parte del derecho al desarrollo humano y tienen una doble dimensión: derechos del constitucionalismo social para la protección de la salud, y un derecho de solidaridad, porque actualmente, la salud es considerada como un problema internacional. Con el objetivo de proteger los derechos de los pacientes, en el contexto de la Unión Europea se han desarrollado numerosas iniciativas. El primer avance fue dado el 18 de diciembre de 2000 con la Carta de los Derechos Fundamentales de la Unión Europea. Proclamada en Niza, reconoce en su artículo 35 que toda persona tiene derecho a la prevención sanitaria y a beneficiarse de la atención sanitaria en las condiciones establecidas por las legislaciones y prácticas nacionales. 


\section{Los Derechos Humanos de los pacientes hospitalizados:}

Derecho a la vida, derecho a la salud, derecho a la autodeterminación, derecho a la información, derecho a la verdad, derecho a la confidencialidad, derecho a la libertad, derecho a la intimidad, derecho a un trato digno, derecho a la mejor atención posible. El Código internacional de ética médica, creado en el año 1949 por la Asociación Médica Mundial de Inglaterra, establece los siguientes postulados, adoptados por la tercera Asamblea General de la Asociación Médica Mundial (AMM), Londres (Inglaterra), octubre de 1949 y enmendado por la 22a de la AMM, Sydney (Australia), agosto 1968 y 35ª de la AMM, Venecia (Italia), octubre 1983; Allí se establecieron los siguientes acuerdos: Deberes de los médicos en general, convertidos en derechos para los pacientes:

- El médico debe mantener siempre el más alto nivel de conducta profesional.

- El médico no debe permitir que motivos de ganancia influyan el ejercicio libre e independiente de su juicio profesional de sus pacientes

- El médico debe en todos los tipos de práctica médica dedicarse a proporcionar un servicio médico competente con plena independencia técnica y moral, con compasión y respeto por la dignidad humana.

- El médico debe tratar con honestidad a pacientes y colegas y esforzarse por denunciar a los médicos débiles de carácter o deficientes en competencias profesional, o a los que incurran en fraude o engaño. Las siguientes practicas se consideran conductas no éticas a. La publicidad hecha por el médico a menos que esté autorizada por las leyes del país y el Código de ética médica de la Asociación médica nacional. b. El pago o recibo de cualquier honorario o cualquier otro emolumento con el solo propósito de obtener un paciente o recetar o enviar a un paciente a un establecimiento.

- El médico debe actuar solo en el interés del paciente cuando preste atención médica que pueda tener el efecto de debilitar la condición mental y física del paciente.

- El médico debe certificar solo lo que él ha verificado personalmente (Obando, B.2016). 


\section{Deberes de los médicos hacia los enfermos:}

- El médico debe recordar siempre la obligación de preservar la vida humana.

- El médico debe a sus pacientes todos los recursos de su ciencia y toda su lealtad. Cuando un examen o tratamiento sobrepase su capacidad, el médico debe llamar a otro médico calificado en la materia.

- El médico debe guardar absoluto secreto de todo lo que se la haya confiado, incluso después de la muerte del paciente.

- El médico debe prestar atención de urgencia como deber humanitario a menos que esté seguro que otros médicos pueden y quieren prestar dicha atención.

- El médico es auxiliar de la justicia en los casos que señala la ley, obra como funcionario público, obra como perito expresamente designado para ello en una u otra condición. El médico cumplirá su deber teniendo en cuenta las altas miras de su profesión, la importancia de la tarea que la sociedad le encomienda como experto y la búsqueda de la verdad y solo la verdad.

- El médico, por la función social que implica el ejercicio de su profesión, está obligado a sujetar su conducta pública y privada a los más elevados preceptos de la moral universal.

El derecho a la salud tiene su base constitucional en los artículos 44 y 49, siendo un derecho de carácter fundamental e inherente a la persona. Es universal, irrenunciable, esencial, y se encuentra cobijado por una garantía y protección normativa. Esta prerrogativa, que el Estado les debe garantizar a sus asociados con su disfrute y acceso a una prestación de un servicio de salud digno, integral y eficiente se ubica entre los derechos más anhelados por nuestros connacionales, pero también es el de los más reclamados debido a su deficiente prestación (Matera, J. 2018)

Por otra parte la Resolución 13437 de 1991, constituye los Comités de ética hospitalaria y se adopta el Decálogo de los derechos de los pacientes. La Ley 100 de 1993, Resolución 4343 de 2012, unifica la regulación respecto de los lineamientos de la carta de derechos y deberes del afiliado y del paciente en el sistema general de seguridad social en salud y de la carta de desempeño de la entidades promotoras de salud de los regímenes contributivo y subsidiado. A ellas se suma el 
Decreto 1022 de 2006, el cual contempla el sistema obligatorio de la garantía de la calidad, al igual que la Ley 1122 de 2007, que establece las políticas para la prestación del servicio de salud y trata en su artículo 42 del defensor del usuario y del paciente, en la cual la Superintendencia de Salud, en concordancia con la Defensoría del Pueblo son los garantes en la implementación de este acápite, en cada una de las ciudades del territorio nacional. Igualmente la ley 1751 de 2015, instituye derechos y deberes de las personas en relación con el derecho fundamental a la salud.

\section{Derechos dentro de la relación del médico con el paciente}

- Escoger libremente al médico. Este derecho pone de presente los siguientes presupuestos básicos recogidos por la ley 23 de 1981 y la ley 100 de 1993, así:

- La relación médico paciente tiene como piedra angular la libre elección del médico por parte del paciente, pero este derecho trasciende, ya que el médico debe respetar la libertad del paciente para prescindir de sus servicios.

- Se garantiza a los afiliados al sistema de seguridad social en salud la libre escogencia de los prestadores de servicios de salud entre las diferentes opciones que ofrezcan las E.P.S. Además, se da la posibilidad de que el afiliado pueda trasladarse voluntariamente de prestador de servicio de salud. Sin embargo este derecho está sujeto a las posibilidades ofrecidas por cada institución.

- El médico tratante debe garantizar al paciente o a sus allegados inmediatos el derecho a elegir al cirujano o especialista de su confianza.

- Información sobre su enfermedad. Este derecho encuentra su desarrollo y está sujeto a las reglas estudiadas en la obligación de información que tienen los médicos (arts. 11 y 18 de la Ley 23 de 1981).

- Tomar decisiones respecto de su organismo. Este derecho se relaciona con el principio de autonomía, que evidencia la libertad que tiene el paciente para adoptar sus propias decisiones sin restricción ni coerción, por más bienhechoras que sean las intenciones del médico. Es decir, en un acto médico la autonomía tiene que ver con la del paciente y no con la del médico. Según 
Faden y Beauchamp (Barona. 2016) una acción se ejerce con autonomía si se dan los siguientes requisitos:

- Intencionalidad, indica que la acción ha ocurrido como resultado de la intención de hacerla, por lo tanto no puede ser accidental, inadvertida o por error, ni ser producto de la presión física o mental ejercida por otro. En últimas puede considerarse que es la acción que se lleva a cabo de acuerdo a un plan preconcebido.

- Conocimiento, indica que la acción se debe ejecutar con entendimiento, o que el paciente debe entender la acción, porque en caso contrario no será autónomo dado que es imprescindible que se comprenda la naturaleza y consecuencia de la acción.

- Sin control externo. Tiene que ver con el control que desde afuera puede ejercerse sobre el paciente, en relación con sus actos, y que pueda hacerse de distintas formas, así: coerción, manipulación y persuasión e incluso la autonomía puede verse interferida por factores internos, como por ejemplo las alteraciones orgánicas o funcionales del cerebro.

- Confidencialidad en la historia clínica. Este derecho se desarrolla cuando se estudia la obligación que tiene el médico con la historia clínica.

- Atención no condicionada a pago de honorarios en caso de urgencias. El artículo 23 de la Ley 23 de 1981, establece que en los casos de urgencias la asistencia médica no se condiciona al pago anticipado de honorarios profesionales.

\section{Derechos adicionales}

La Asociación Médica Mundial (AMM) (Barona. 2016) le ha otorgado al paciente una serie de derechos adicionales así:

- El respeto de sus decisiones en caso de enfermedades irreversibles.

- Explicación de costos por parte del médico. Busca que el paciente pueda revisar y recibir explicaciones acerca de los costos por los servicios obtenidos, tanto por parte de los prestadores de servicios de salud como por parte de las instituciones sanitarias. 
- Recibir o rehusar ayuda espiritual cualquiera que sea el culto que profese.

- Respeto a la voluntad de aceptar o rehusar la donación de órganos para que estos sean trasplantados a otros enfermos.

- Morir con dignidad y a que se le respete su voluntad de permitir que el proceso de la muerte siga su curso normal, en la fase de su enfermedad.

No debe perderse de vista la necesidad que existe de una formación profesional compleja, ya que ésta no debe circunscribirse sólo al aprendizaje y conocimiento de la técnica, sino que debe también abarcar las ciencias humanas y sociales. Al lado de la educación teórica científica que forma al médico en la técnica médica, es conveniente hacer que el profesional de la salud tome conciencia del impacto que sus actos generan sobre la sociedad (Fernández, M. 2014) “

El médico debe ser formado con un criterio humanístico de alto grado, de tal manera que las facultades de medicina se apropien de generar un sentido ético social que le transmita al galeno la importancia de establecer la comunicación con el paciente desde el primer contacto, generando en esa relación confianza y seguridad en todo el proceso o tratamiento. En este orden de ideas es bien sabido sobre los retos que el profesional de la medicina debe enfrentar en materia de riesgos, aunado a la situación.

No debe aguardarse que el riesgo médico ocurra para iniciar la búsqueda de soluciones; resulta necesario que tanto médicos como pacientes tengan un conocimiento previo y suficiente acerca de él. (Fernández, M. 2014) "La práctica de una pedagogía del riesgo médico a través de la información se considera que podría llegar a ser un eslabón importante para hacerle frente desde un punto de vista no contencioso, pues su ocurrencia es generadora de un conflicto entre los intereses del paciente y del médico o entidad hospitalaria". En consecuencia, es necesario prepararse para el sobrevenir de este tipo de riesgos propios de la actividad médica. Es donde toma importancia la presente investigación, dando relevancia a las rutas de información, que en efecto debe comenzar por parte del médico tratante, toda vez que esto se traduce en un momento fundamental para la búsqueda del bienestar de las partes. La información de los pacientes constituye un modo eficaz no solo para prevenir las acciones de responsabilidad, sino también para conocer el riesgo médico sin necesidad de recurrir a la vía contenciosa. Todo acto médico supone la existencia de un dialogo previo 
entre el médico, quien informa sobre el estado de salud y el procedimiento a seguir, y el paciente, quien otorga el consentimiento al acto médico. La información verbal constituye el elemento principal y debe ser suficiente so pena de ser calificada como culposa".

Las aseguradoras y prestadores de servicios de salud, al igual que las entidades designadas por la Ley 1122 de 2007 en su artículo 42 como defensoras del paciente, carecen de los mecanismos eficaces que faciliten la información de las rutas de protección de los derechos del paciente, cuando de riesgos médicos se trata y se sitúa al paciente en la posición de víctima de un acto médico irregular o equivoco, que vulnera en todas sus formas estos derechos y por consiguiente la lex artis. Existen sólo en las E.P.S y las I.P.S unos sistemas de información y atención al usuario (SIAU) donde apenas se colocan quejas y reclamos atinentes a las demoras o falta de oportunidades que el paciente requiere para agilizar procedimientos, consultas médicas especializadas o de subespecialidades, solicitud de medicamentos no pos, o que hallándose dentro del plan de beneficios, su entrega es tardía. De igual manera, información de red de prestadores de servicios, instituciones contratantes, información sobre costos de cuotas moderadoras y copagos, información de trámites de incapacidades y licencias de maternidad, la cualificación de encuestas de satisfacción al usuario. También se encarga esta dependencia de la organización de las asociaciones de usuarios, entre otras de carácter administrativo y de mercadeo. Esto deja ver una importante deficiencia también en las entidades del Estado encargadas de vigilar y proteger los derechos de los pacientes en temas de trascendental magnitud como la relación médico-paciente y el conocimiento puntual de los intríngulis que se desprenden del acto médico, falla en el servicio y que afectan frontalmente al paciente tanto en su integridad física, moral y económica.

A este respecto, deben contar estas entidades con un sistema de información personalizada y preventiva que oriente y asesore a los pacientes en los casos que éste advierta una falla en el servicio, errada praxis o un error en el acto médico. Asimismo en el evento en que la actuación del profesional de la medicina infrinja o contrarié la lex artis ad hoc, para buscar vías de esclarecimiento y las acciones respectivas. Todo ello teniendo en cuenta que estamos frente a un derecho fundamental y que el médico actúa como servidor público. Las entidades del Estado garantes de la protección de los derechos de las victimas (pacientes), las adscritas al Ministerio de Salud y los Tribunales de ética médica, en todas sus dependencias, deben contar con el susodicho y brindar información 
de fácil acceso cuando se consideren vulnerados los derechos de los pacientes, en caso de responsabilidad médica, de tal manera que actúen decididamente como entidades avalistas y vigilantes, al igual que el Instituto Nacional de Vigilancia de Medicamentos y Alimentos (Invima), que pueda conocer, afirmar o desvirtuar casos conexos con la responsabilidad médica derivados de la falla en el servicio.

\section{Rutas y mecanismos de protección de los derechos del paciente en la falla en el servicio}

En la prestación de los servicios de salud se pueden ocasionar daños a los pacientes, producidos por la negligencia en la acción u omisión del prestador sanitario; daños que originan perjuicios materiales e inmateriales al paciente, que deben indemnizarse mediante un proceso declarativo de responsabilidad civil, o por medio de demanda de reparación directa, cuando el Estado es el causante del daño antijurídico. No se requiere para iniciar los citados procesos de un número plural de víctimas del daño galénico; por ende, puede presentarse por un único paciente perjudicado.

El fin de los anteriores procesos judiciales es el reconocimiento por parte del juez de los derechos del paciente; derecho a la verdad acerca de los hechos causantes del daño y a la justicia e indemnización integral de los perjuicios que se le ocasionaron. La vulneración a los derechos individuales y colectivos del paciente o usuario del servicio médico, debe repararse; para ello, existen acciones judiciales de naturaleza individual o acciones constitucionales colectivas, que tienen los mecanismos necesarios para lograr un propósito: garantizar los derechos de las víctimas del daño. La acción colectiva de clase, requiere de condiciones uniformes de las personas que integran el grupo, en este caso, de pacientes víctimas directas e indirectas del daño médico-sanitario; condiciones uniformes que deben ser preexistentes a la ocurrencia del evento adverso causante de perjuicios.

Así las cosas, tanto las acciones indemnizatorias declarativas de naturaleza civil o estatal, como las acciones constitucionales de grupo con carácter reparador, salvaguardan los intereses análogos del paciente víctima del daño. Por ello, y por el compromiso del legislador de proteger el interés social de la comunidad, fue que se consideró necesario estatuir, para su protección, una acción especial y un proceso diferente para tramitar estas últimas. Esa es la razón por la cual "la garantía constitucional [de las acciones de grupo] se reduce a la alternativa de acudir a un mecanismo más ágil de defensa en un lapso prudencial, sin 
que con ello se elimine la posibilidad para los miembros de ese grupo, de ejercer, dentro de los términos ordinarios de caducidad, las acciones individuales que correspondan (Corte Constitucional de Colombia, 2004).

En suma, las acciones de tutela, populares y de grupo, se constituyen en mecanismos de protección de los derechos fundamentales del paciente; usuario a quienes se le vulneran sus derechos de manera individual, o cuando existe pluralidad y homogeneidad de víctimas y daño, causante de perjuicios materiales e inmateriales al paciente. El resarcimiento del daño es viable a través de la acción popular, o se busca su reparación por medio de la acción de grupo colectiva o de clase y también por el medio de control de la reparación directa, al cual se hará referencia más adelante. A su vez, también existe la teoría del daño punitivo, al que se hará alusión en la propuesta; es una herramienta eficaz para la protección de los derechos del usuario en salud (López, J. 2014)

La víctima del hecho médico-sanitario generador de un daño puede demandar la indemnización de los perjuicios en la jurisdicción ordinaria civil o la jurisdicción contenciosa administrativa. La categoría jurisdicción representa el género y la especie está constituida por la jurisdicción civil cuando el demandado corresponde a un prestador en salud privado, y administrativa en el evento de ser el hospital o un servidor público el causante del daño. Así las cosas, la civil, estatal, penal, entre otras, son las especies de jurisdicción. Sin embargo, de acuerdo con lo señalado anteriormente, existe la jurisdicción constitucional cuyo objetivo es amparar los derechos del paciente.

La víctima del hecho médico generador de perjuicios materiales e inmateriales, tiene tres derechos fundamentales que deben ampararse. El primero, el derecho a la verdad sobre los hechos que ocasionaron el daño y el derecho a conocer su estado de salud; el segundo, relacionado con el derecho a la justicia garantizando su acceso sin dilaciones injustificadas. Por último, la víctima del daño tiene derecho a la reparación integral; derecho que debe garantizársele, cumpliendo de esta forma con la función resarcitoria de la responsabilidad médica señalada en este acápite. Las constantes demandas por falla en el servicio médico que tienen como resultado responsabilidad del Estado, complementan la especial ilustración al paciente para que éste transite exitosamente en la ruta que protege su derecho. Por lo tanto el interés teleológico de esta investigación corresponde al compromiso de las entidades señaladas 
en el titulo anterior, la función de guía, información y orientación del procedimiento a seguir para lograr la efectividad en la aplicación de la ruta y del medio de controlpertinente, suministrando las indicaciones necesarias e incluyendo el término de caducidad al que este mecanismo de protección se refiera. Por lo tanto, este estudio desde la generalidad de las fallas en el servicio por parte del Estado, las cuales abarcan variedad de campos en el cual cualquier administrado que se sienta afectado por el Estado puede poner en funcionamiento el aparato jurisdiccional para que se le indemnice por el daño causado.

Falla en el Servicio por parte de la Administración: la falla en el servicio se desprende de la prestación de un servicio estatal, que al no ser prestado en la forma debida genera un daño, derivándose que el Estado tenga que responder directamente por ese daño, lo cual se configura como nexo causal. Las características de la falla en el servicio (Torres, L. 2016 cita a la UNAD, 2014) que la define como:

- Se pasa de una culpa individual a una culpa de la administración en virtud de una falla en el servicio prestado.

- Se presumirá la culpa del Estado, por el hecho de prestar en indebida forma los servicios que debe prestar, entre los que se encuentran los servicios públicos.

- La persona que sufre perjuicios deberá probar el nexo causal entre el daño y la falla en la prestación del servicio.

- Solo podrá eximirse de responsabilidad al Estado cuando se demuestre que la falla en el servicio se dio por consecuencias extrañas, tales como fuerza mayor, hecho de un tercero, culpa exclusiva de la víctima.

- Cuando el daño se produzca por un servidor del Estado en ejercicio o en virtud de sus funciones, el Estado tendrá que responder por el daño y luego este ejercerá la acción de repetición contra el funcionario ejecutor del daño.

- Si el daño es generado por un funcionario del Estado, fuera de sus funciones administrativas, éste responderá a título personal.

Aunado a los anteriores conceptos se encuentra que la responsabilidad del Estado se configura de diferentes maneras; se detallaran los conceptos pertinentes a la falla en el servicio de salud, como lo son:

- Responsabilidad Médica por Acción u Omisión: Hace referencia al compromiso u obligación de tipo moral que surge de la posible 
equivocación cometida por un individuo en un asunto específico. La responsabilidad es, también, la obligación de reparar un error y compensar los males ocasionados cuando la situación lo amerita. En el ámbito del derecho, en cambio, se habla de responsabilidad jurídica para describir la violación de un deber de conducta que ha sido respaldado con anticipación desde una norma jurídica. A diferencia de una norma moral, la ley surge de un organismo externo al sujeto, el Estado, y es coercitiva (Ruiz, W. s.f).

- Indemnizar - Resarcimiento: es la acción y efecto de resarcir. Este verbo, con origen en un vocablo latino hace referencia a reparar, compensar o indemnizar un daño o perjuicio. En el ámbito jurídico, hay un concepto que se conoce como Indemnización por daños y perjuicios que también se llama simplemente resarcimiento. Se trata de una acción que puede ejercer la víctima o a un acreedor para exigir parte de la cantidad de dinero equivalente a la totalidad de los beneficios que se han perdido a causa de una determinada acción de una persona específica (Torres, L. 2016, cita a Ternera 2008).

- Perjuicio: término latino praeiudicium que se transformó, en nuestro idioma, en perjuicio. Este concepto refiere a las consecuencias de perjudicar, una acción que consiste en provocar un detrimento a alguien o algo. En el ámbito del derecho, se entiende por perjuicio a un menoscabo que requiere de la indemnización de quien lo genera. Esto quiere decir que la persona que provoca el perjuicio debe indemnizar a la víctima.

- Riesgo Excepcional: modalidad de la responsabilidad; quien tiene a su cargo un peligro que se puede causar y que la otra parte no tiene por qué soportar (Torres, L. 2016) cita a Ossorio (2002).

- Daño Directo: es el que resulta de manera inmediata de la acción u omisión culposa o dolosa.

- Actos Médicos: lo constituyen todos aquellos actos cuyo cumplimiento presenta serias dificultades y requieren conocimientos adquiridos a costa de estudios prolongados; entre los cuales están los diagnósticos, exámenes complejos, interpretación de resultados, tratamiento, medicamentos, prestación del servicio completo.

El Consejo de Estado, Sala Contencioso Administrativo, Sección tercera, 1995-00935. 11 de mayo de 2006 conceptúa que la declaratoria de 
responsabilidad por el servicio médico a cargo del Estado se ha enmarcado siempre en el régimen subjetivo de responsabilidad, esto es en el régimen de falla en el servicio donde predomina el elemento de la culpa. Se debe hacer claridad sobre los elementos que componen la falla en el servicio, los cuales son el daño antijurídico sufrido por el interesado, el deficiente funcionamiento del servicio (falla) y la relación de causalidad que se refiere a la evidencia o comprobación que el daño se produjo como consecuencia de una falla.

Las constantes demandas por falla en el servicio médico, reducen el capital que se puede invertir en hospitales públicos en la calidad, cantidad de personal, equipos de dotación, insumos y en general todo tipo de elementos que se necesitan para un funcionamiento excelente. Esto conduce a que el servicio de salud se preste en condiciones deplorables; en la actualidad la falla en el servicio médico aumenta por las situaciones actuales del servicio médico-sanitario colombiano. Por ello es importante que las garantías existentes en la legislación se hagan efectivas, toda vez que los riesgos se incrementan con el alto número de consultas, procedimientos, intervenciones, diagnósticos, urgencias y demás sucesos médicos, lo que da como resultado un alto porcentaje de demandas, por mínimo que sea el daño causado y el valor solicitado para resarcir el mismo.

Esta responsabilidad siempre se trata como civil extracontractual, establecida en el artículo 49 de la Constitución Nacional que define el servicio de salud como servicio público a cargo del Estado, sea que se preste en forma directa o bajo su supervisión y control.

Consejo de Estado, Sala Contencioso Administrativo, Sección tercera, 1999- 1690. 14 de febrero de 1992 indica, se revelan diferentes tesis como la falla inferida y la falla presunta. La primera considera aceptable la prueba a través de la acreditación de las circunstancias del caso, en la segunda se invierte la carga probatoria a la entidad demandada.

Consejo de Estado, Sala Contencioso Administrativo, Sección tercera, Subsección C, 1999-01065. 12 de agosto de 2014 indica que la conducta médica a asumir por las entidades prestadoras de servicios de salud y los médicos tratantes, debe tener identidad con la patología a tratar, debe ser integral en relación con el tratamiento y la dolencia misma, y sobre todo debe ser oportuna, como quiera que frente al enfermo, aquellos tienen una posición de garante. 
Según el Consejo de Estado Sala Contencioso Administrativo, Sección tercera, Subsección C, Sentencia del 24 de marzo de 2011 describe los eventos de responsabilidad médica por el régimen objetivo así:

- Aquellos eventos que implican la manipulación de cosas peligrosas, o que el procedimiento, o tratamiento empleado entrañe peligro, pero siempre y cuando la herramienta riesgosa cause el daño de manera directa o por ella misma, pues si la lesión es producto de una ejecución irregular del acto médico, aunque medie un instrumento que represente peligro o riesgo, el caso específico estará regido por la responsabilidad subjetiva o culposa.

- Cuando respecto a un medicamento, tratamiento o procedimiento que implica o conlleva un progreso en la ciencia y, por lo tanto, se considera novedoso, se desconocen las consecuencias o secuelas a largo plazo del mismo.

- Cuando en el acto médico se emplean químicos o sustancias peligrosas, (ejemplo medicina nuclear).

- En supuestos de vacunas porque se asume de manera implícita su eventual peligrosidad y reacciones adversas en los diferentes organismos.

- Cuando el daño es producto de una infección nosocomial o intrahospitalaria. (Consejo de Estado, Subsección C, Sentencia del 24 de marzo de 2011, p 16)

- Falla en el Servicio por Diagnóstico Tardío: El diagnóstico tardío ocurre cuando se omite una condición médica como consecuencia de una revisión negligente, así esta empeora antes de ser detectada. No tratar ciertas enfermedades puede traer como consecuencia el homicidio culposo del paciente".

- Falla en el Servicio por Error en el Diagnóstico: En algunos casos, se hace un diagnóstico completamente equivocado al basarse en síntomas que pueden ser similares a la condición médica real. En estos casos, un médico puede haber realizado un examen inadecuado y realizar un diagnóstico basándose en los resultados negligentes. Esto puede ocasionar que el médico recete medicamentos innecesarios, errores en la medicación y, además, ocasiona que la condición médica erróneamente diagnosticada no sea tratada. Otro caso de diagnóstico erróneo ocurre cuando 
no se detecta una condición médica secundaria y se receta un medicamento incorrecto o inadecuado.

- Falla en el Servicio por Omitir Tratamiento: Este concepto se construye a partir de lecturas variadas y se puede interpretar de la mano con la falla anterior y la siguiente, ya que al tener un diagnóstico equivocado no se formula el tratamiento adecuado y por ende se perjudica la salud del paciente por haber perdido la oportunidad y el tiempo de medicar el tratamiento correcto. Aunque la omisión del tratamiento no solo es por error se puede producir por trámites administrativos como autorizaciones o por no contar con agenda abierta de la especialidad necesitada, ya que por los costos que se generan a cargo de las EPS no tienen suficientes profesionales ni equipos para abordar la demanda de servicios.

- Falla en el Servicio por Irregularidades en la Prestación del Servicio: Realizada la lectura e investigación en el tema se puede concluir que esta falla se relaciona con la falta de insumos, personal idóneo e instalaciones para la adecuada prestación de servicios de salud. Ésta se configura por que las instituciones no tienen las adecuaciones necesarias (capacidad instalada) para el cabal cumplimiento del objeto para el cual fueron creadas. Se aúna a lo anterior la tramitología administrativa, las autorizaciones tardías y extemporáneas en algunos casos y los mínimos insumos con los que cuenta la red de salud, siendo un obstáculo que solo se puede superar con recursos provenientes del Estado, ya que con los que se cuentan son escasos para atender las solicitudes de los ciudadanos.

- Falla en el Servicio post Operatoria: Este concepto se crea con base en diferentes lecturas realizadas, ya que las cirugías son de medio y no de resultado, y luego de ellas se tiene un tiempo de espera para verificar los efectos. Aquí hay varios aspectos a analizar, como son la práctica de la cirugía en si misma, las instalaciones donde se realizó, los cuidados luego de su realización tanto por el equipo tratante como del paciente y la reacción del paciente frente a la cirugía, lo que lleva a generar un cúmulo de posibilidades para la configuración de la falla, desde una infección contraída en el quirófano, una mala praxis de la cirugía, hasta cuidados no acordes con la necesidad del paciente, omisión de cuidado o irregularidad en el mismo. 
- Falla en el Servicio por Atención Tardía o Perdida de la Oportunidad: El Consejo de Estado. Sección tercera. Exp.11878, febrero 10 de 2000, conceptúa: La Corporación en materia de responsabilidad médica acogió en su jurisprudencia, la tesis de la "pérdida de un chance u oportunidad", consistente en que la falla en la prestación del servicio de salud configura responsabilidad, por el sólo hecho de no brindar acceso a un tratamiento, incluso si desde el punto de vista médico la valoración de la efectividad del mismo, muestra que pese a su eventual práctica (es decir si se hubiera practicado y no se hubiera incurrido en la falla en la prestación del servicio), el paciente no tenía expectativas positivas de mejoría.

- Falla en el Servicio por Falta de Consentimiento Informado: En su estudio Monsalve \& Navarro el Consentimiento Informado, cita Torres, L. (2016) detallan que en la Constitución de 1991 se encuentran los pilares del consentimiento informado, como son la dignidad humana (art 1), la intimidad (art 15), la autonomía de la voluntad y el libre desarrollo de la personalidad (art 16). Por estar en la Constitución Nacional, que es norma de normas, prevalece sobre las demás leyes. En el año 1991 el Ministerio de Salud adoptó el Decálogo de Derechos de los Pacientes, aprobado por la Asociación Médica de Lisboa, que indica en su artículo 1 parágrafo 2: todo paciente sin discriminación alguna tiene derecho: a disfrutar de una comunicación plena y clara con el médico, apropiada a sus condiciones sicológicas y culturales, que le permitan obtener toda la información necesaria respecto a la enfermedad que padece, así como los procedimientos y tratamientos que se le vayan a practicar, el pronóstico y riesgos a los que dicho tratamiento conlleve, también el derecho a que sus familiares den el consentimiento o rechacen los mismos. La no explicación correcta y la falta de material probatorio de la misma, conllevan a la configuración de esta falla.

- Falla en el Servicio por Excederse en Tratamientos o Cirugías: El acto médico por su propia naturaleza acarrea consecuencias legales dado que incide sobre un sujeto de derechos, se entiende que en el caso de los tratamientos o cirugías el personal pone a disposición todo su conocimiento y capacitación, pero en estos casos es una actividad de medio, no de resultado, ya que cada organismo o persona reacciona diferente a los tratamientos, 
medicamentos o cirugías; con esto se da por entendido que este tipo de fallas son demandables según etapa probatoria y no el resultado de la misma ya que no es predecible, se esperan los mejores resultados, pero no siempre se obtienen.

- La Acción de Reparación Directa: Tiene la acción de reparación directa su fundamento jurídico en el artículo 90 de la Constitución Política, en el cual se define la responsabilidad patrimonial del Estado por la acción u omisión imputable a sus agentes. Este medio de control, consagrado en el artículo 140 del Código de Procedimiento Administrativo y de lo Contencioso Administrativo (CPACA), consiste en que la persona interesada podrá pedir directamente la reparación de un daño antijurídico por la acción u omisión de los agentes del Estado, o por cualquier otra causa imputable a una entidad pública o un particular que haya obrado siguiendo una expresa instrucción de la misma. Algunas características de este medio de control son: a) tiene un término de caducidad de dos años contados a partir del día siguiente de la ocurrencia de la acción u omisión causante del daño o de cuando el demandante tuvo o debió tener conocimiento del mismo si fue en fecha posterior y siempre que la imposibilidad de haberlo conocido en la fecha de su ocurrencia ( CPACA, Art 164 literal i), b) en todos los casos en los que la causación del daño estén involucrados particulares y entidades públicas, en la sentencia se determinará la proporción por la cual debe responder cada uno de ellos (Rodríguez, L. 2015).

Algunos aspectos correlativos de este medio de control no requieren reclamación previa, es decir no requiere ni exige como presupuesto procesal reclamación previa ante la administración y menos interposición de recurso administrativo alguno, por lo tanto el interesado podrá acudir directamente a la jurisdicción contenciosa administrativa. Es necesario antes de la formulación de la demanda agotar el trámite de la conciliación prejudicial. Igualmente debe estructurarse la legitimación por activa, radicada en la persona a quien el ordenamiento jurídico, según el daño padecido, le reconoce la titularidad del derecho a formular la pretensión y solicitar la indemnización de acuerdo con las reglas procesales. Podrán activarla, persona natural o jurídica, pública o privada, que se consideren lesionadas en sus intereses legítimos por la acción u omisión de las entidades públicas; legitimación por pasiva, concordante con el artículo 140 inciso 4 del CPACA. Así mismo la jurisdicción contenciosa administrativa conocerá de 
los procesos relativos a la responsabilidad extracontractual de cualquier entidad pública (Solano, J.2016)

En la misma forma se cita el artículo 165 numeral 1, in fine del CPACA. Oportunidad para demandar. Descrito en el artículo 164 numeral 2, literal $i$, inciso $1^{\circ}$, infine del CPACA; el término general de caducidad es de dos (2) años, contados a partir del día siguiente de ocurrida la situación o conducta específica causante del daño, salvo en el supuesto que determina el artículo antes citado. Acerca del momento en que empieza a contarse el término de caducidad en los casos de responsabilidad médica o de incumbencia de la administración de justicia, la jurisprudencia expresa que existen dos supuestos en los cuales el citado principio de la prevalencia de lo sustancial sobre lo formal hace q se aligere o aliviane la disposición del numeral 8 del artículo 136 del C.C.A.; estas dos hipótesis son: i) hasta tanto la persona no tenga conocimiento del daño, al margen de que el hecho o la omisión médica se haya concretado en un día distinto o años atrás del momento en que se establece la existencia de la lesión antijurídica y ii) cuando existe un tratamiento médico que se prolonga en el tiempo y respecto del cual se le genera al paciente una expectativa de recuperación.

En el segundo escenario ii) el paciente tiene pleno conocimiento del daño pero el servicio médico le brinda esperanzas de recuperación al someterlo a un tratamiento que se prolonga en el tiempo. En este tipo de circunstancias, el conteo de la caducidad no inicia hasta tanto no se haya proferido el diagnóstico definitivo del paciente. (Sentencia del 14 de abril de 2010, expediente 19154). La doctrina hace consistir la caducidad como el fenómeno jurídico de la extinción del derecho a accionar por vencimiento del término perentorio concedido por la ley. Así, la caducidad es otro presupuesto procesal para acudir a la jurisdicción y establecido como fenómeno jurídico de extinción de los medios de control por el transcurso del tiempo. Cuando la demanda no se presenta dentro de los términos legales ocurre el fenómeno jurídico de la caducidad, opera de pleno derecho afirman algunos autores, es decir que al vencerse el término perentorio establecido por la ley se extingue por el mero transcurso del tiempo automáticamente el derecho al ejercicio del medio de control o de acudir a la jurisdicción en pretensión contencioso administrativo, en sus consecuencias genera el rechazo de la demanda y para decretarla procesalmente hablando, no se requiere petición de parte, no obstante puede plantearse como excepción previa por la parte demandada. 


\section{Caso Hospital Universitario de Sincelejo: Grado de Conocimiento en los Pacientes de las Rutas de Información y sus Mecanismos de Protección como Victimas de la Falla en el Servicio}

Desarrollamos una encuesta de tipo cerrada encaminada a determinar qué nivel de conocimiento tienen los pacientes del Hospital Universitario de Sincelejo, acerca de las rutas de información y de los mecanismos de protección en los años -2014-2017, los resultados obtenidos se valoraron en términos cuantitativos y cualitativos, la encuesta tiene un plan de análisis de datos referente al objetivo de lo que se pregunta, definiendo la posible respuesta como una valoración afirmativa o negativa, y este resultado permitirá realizar unas conclusiones por cada pregunta.

La encuesta está compuesta por cinco preguntas (5) de tipo cerrada. El contenido de la encuesta es el siguiente:

Nombre de la encuesta:

¿Qué nivel de conocimiento tienen los pacientes del H.U.S. acerca de las rutas de información y de los mecanismos de protección en caso de falla del servicio?

Preguntas:

Diga Si o No

1. Conoce usted cuales son los derechos como paciente?

SI $\mathrm{NO}$

2. Conoce usted como proteger sus derechos jurídicamente? SI $\mathrm{NO}$

3. En el H.U.S le han dado a conocer sus derechos como paciente en caso de una presunta falla medica? SI $\mathrm{NO}$

4. Alguna entidad le ha brindado información de cómo acceder a la justicia en caso de un daño causado por mala prestación en el servicio de salud? SI $\mathrm{NO}$

5. Sabe a qué entidad acudir en caso de presentarse un falla médica a usted o a algún familiar?

SI $\mathrm{NO}$

6. Le han informado sobre los riesgos y sus derechos al momento de realizarle un procedimiento médico? SI $\mathrm{NO}$ 
7. Ha conocido por parte de la Defensoría del Pueblo, información amplia como entidad Defensora del Paciente? SI $\mathrm{NO}$

Esta encuesta se realizó a los pacientes en el HUS de forma aleatoria que fueron atendidos en las áreas de urgencias, consulta externa y procedimientos quirúrgicos.

Los resultados obtenidos en la muestra de la encuesta serán valorados de forma cualitativa y el total de afirmaciones o negaciones reflejaran el nivel de conocimiento que tiene el paciente frente al contexto de la pregunta.

\section{Conocimiento de los Pacientes de las Rutas de Información y de los Mecanismos de Protección}

La información a los pacientes constituye un modo eficaz no solo para prevenir las acciones de responsabilidad, sino también, para conocer el riesgo médico sin necesidad de recurrir a la vía contenciosa. Todo acto médico supone la existencia de un diálogo previo entre el médico (quien informa sobre el estado de salud y el procedimiento a seguir) y el paciente (quien otorga el consentimiento al acto médico). La información verbal constituye el elemento principal y debe ser suficiente so pena de ser calificado como culposa. Al respecto, criticando la práctica frecuente que en nuestras instituciones de salud se ejercita, en el sentido de hacer que el paciente suscriba un formato pre impreso a través del cual se otorga el consentimiento, la jurisprudencia Colombiana ha sido precisa en señalar que el consentimiento que exonera, no es el otorgado en abstracto, in genere, esto es por todo y para todo el tiempo, sino el referido a los riesgos concretos de cada procedimiento. Por tanto, el consentimiento debe ser individual para cada tipo de tratamiento, y no global, como se acostumbra en muchos formatos pre impresos.

\section{Toma de datos:}

En el desarrollo de esta encuesta se logró determinar que uno de cada diez pacientes encuestados solo respondió de forma afirmativa frente a la misma. Dejando entrever que la calidad de información suministrada por parte de las entidades a sus pacientes es paupérrima, quedando el paciente con un vacío tal que no sabría qué acción tomar para proteger sus derechos; es deber de la entidades brindarle conocimiento claro y expreso acerca de sus derechos si se presenta una presunta vulneración en la prestación del servicio médico, y cuál es la forma de acceder a la justicia utilizando las rutas de información adecuadas en pro de la garantía de la protección. 


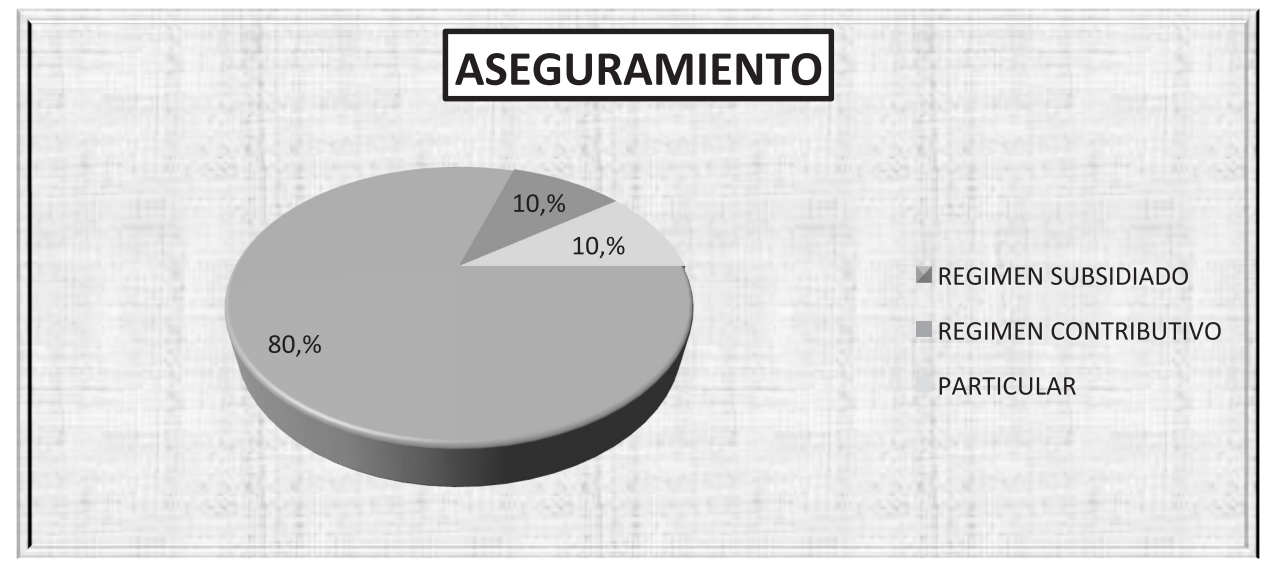

Gráfica 1. Distribución de población encuestada en el H.U.S. por régimen de salud

Elaboración propia.

1. ¿Conoce usted cuales son los derechos como paciente? $\mathrm{SI} \_\mathrm{NO}$

Tabla 1

Grado de conocimiento

\begin{tabular}{cccccc}
\hline GÉNERO & POBLACIÓN & CONOCE & $\%$ & $\begin{array}{c}\text { NO } \\
\text { CONOCE }\end{array}$ & $\%$ \\
\hline FEMENINO & 15 & 1 & 5 & 14 & 45 \\
MASCULINO & 15 & 0 & 0 & 16 & 50 \\
TOTAL & 30 & 1 & 5 & 30 & 95 \\
\hline
\end{tabular}

Elaboración propia. 


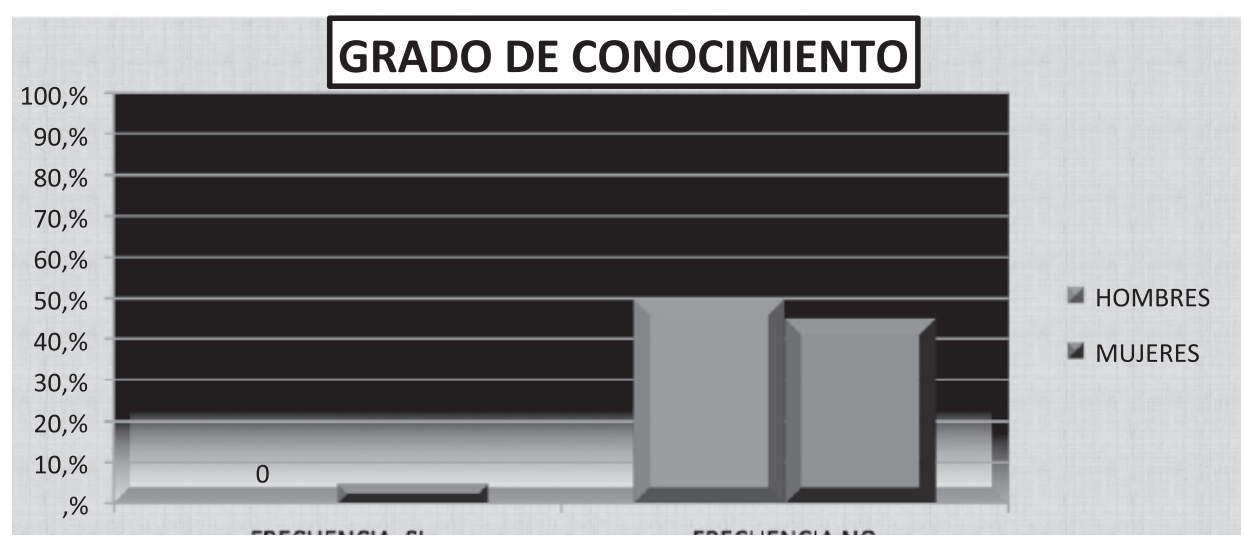

Gráfico 2. Grado de conocimiento.

Elaboración propia.

Grado de conocimiento: dentro del grupo aleatorio selecionado se estimaron rangos de edades entre 20 y 50 años, encontramos como el 95\% de la poblacion en general no conoce los derechos del paciente, especificados asì: $50 \%$ poblacion masculina no tiene conocimiento. 50\% poblacion femenina, de los que el $5 \%$ solo conoce los derechos como paciente.

2. ¿Conoce usted como proteger sus derechos como paciente jurídicamente?

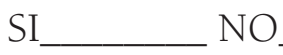

Tabla 2

Protección de los Derechos

\begin{tabular}{cccccc}
\hline GÉNERO & POBLACIÓN & CONOCE & $\%$ & NOCONOCE & $\%$ \\
\hline FEMENINO & 15 & 5 & 16.6 & 10 & 33.3 \\
MASCULINO & 15 & 6 & 20 & 9 & 30 \\
TOTAL & 30 & 1 & 5 & 30 & 95 \\
\hline
\end{tabular}

Elaboración propia. 


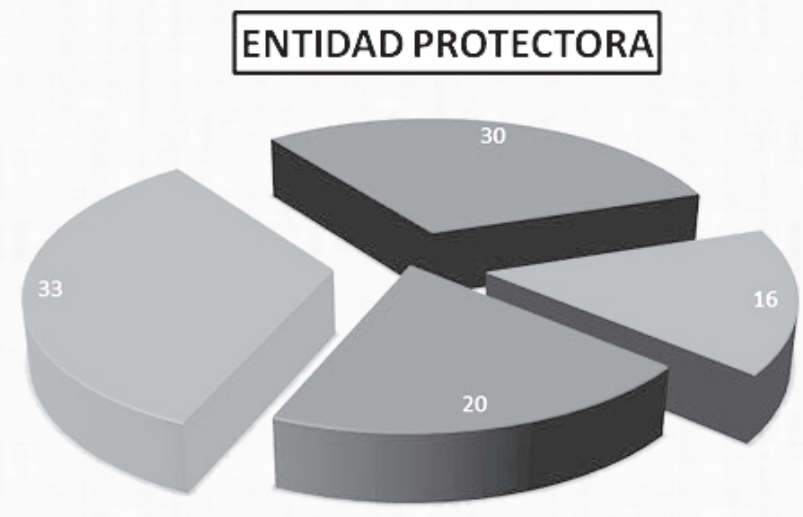

Gráfico 2. Protección de los Derechos

Elaboración propia

Protección de los derechos. En la población encuestada seleccionada aleatoriamente del Grupo de pacientes encuestados que acuden al H.U.S, se logró cuantificar así: en la población femenina de 15 encuestas, 10 contestaron no saber cómo proteger sus derechos como paciente, esto equivale al $33.33 \%$ del $50 \%$ de la aplicación encuesta, y cinco contestaron que si saben como proteger sus derechos como pacientes es decir el $16.66 \%$.

En la población masculina el otro 50\% encuestado se cuantifico así 9 contestaron no saber cómo proteger sus derechos es decir el 30\% y 6 contestaron si saber cómo proteger sus derechos.

3. ¿En el H.U.S le han dado a conocer sus derechos como paciente en caso de una presunta falla medica?

SI $\mathrm{NO}$

Tabla 3

Derecho a la Información

\begin{tabular}{cccccc}
\hline GÉNERO & POBLACIÓN & CONOCE & $\%$ & NO CONOCE & $\%$ \\
\hline FEMENINO & 15 & 2 & 6.66 & 13 & 43.4 \\
MASCULINO & 15 & 3 & 10 & 12 & 40 \\
TOTAL & 30 & 5 & 16.66 & 25 & 83.4 \\
\hline
\end{tabular}

Elaboración propia. 


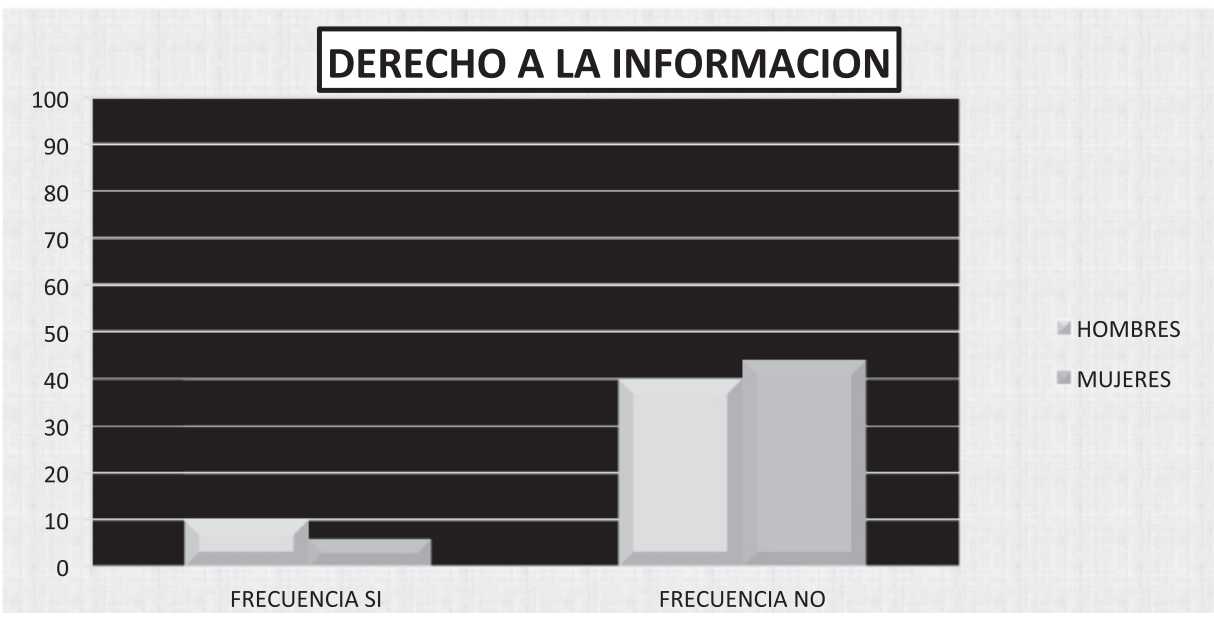

Gráfica 3. Derecho a la Información Elaboración Propia

Derecho a la información: En la población seleccionada aleatoriamente del grupo de pacientes investigados se cuantifico de la siguiente manera en la población femenina que constituye el $50 \%$ de los encuestados, es decir 15 para el caso 2 contestaron afirmativamente es decir $6.66 \%$, y 13 contestaron negativamente $43.4 \%$.

En la población restante del $50 \%$ es decir hombres de 15 solo 3 contestaron afirmativamente es decir el 10\%., y 12 de manera negativa es decir el 40\%.

4. ¿Alguna entidad le ha brindado información de cómo acceder a la justicia en caso de un daño causado por mala prestación en el servicio de salud? SI NO

Tabla 4

Acceso a la Justicia

\begin{tabular}{cccccc}
\hline GÉNERO & POBLACIÓN & CONOCE & $\%$ & $\begin{array}{c}\text { NO } \\
\text { CONOCE }\end{array}$ & $\%$ \\
\hline FEMENINO & 15 & 5 & 16.6 & 10 & 33.3 \\
MASCULINO & 15 & 6 & 20 & 9 & 30 \\
TOTAL & 30 & 1 & 5 & 30 & 95 \\
\hline
\end{tabular}

Elaboración propia. 


\section{PROTECCION DE LOS DERECHOS}

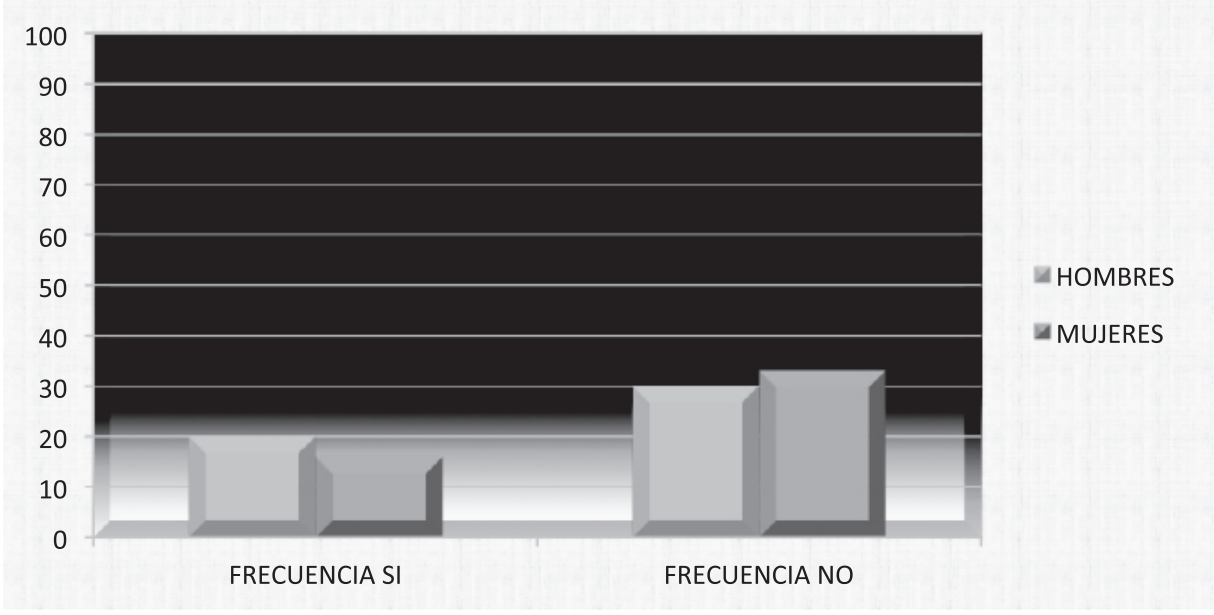

Gráfico 4. Acceso a la Justicia

Elaboración Propia.

Acceso a la justicia: dentro del grupo aleatorio selecionado se estimaron rangos de edades entre 20 y 50 años, encontramos como el $50 \%$ de la poblacion en general no conoce los derechos del paciente, especificados asì: $50 \%$ poblacion masculina no tiene conocimiento. 50\% poblacion femenina, de los que el $5 \%$ solo conoce los derechos como paciente.

5. ¿Sabe a qué entidad acudir en caso de presentarse una falla médica a usted o a algún familiar?

SI $\mathrm{NO}$

Tabla 5

Entidad Protectora

\begin{tabular}{cccccc}
\hline GÉNERO & POBLACIÓN & CONOCE & $\%$ & $\begin{array}{c}\text { NO } \\
\text { CONOCE }\end{array}$ & $\%$ \\
\hline FEMENINO & 15 & 5 & 16.6 & 10 & 33.3 \\
MASCULINO & 15 & 6 & 20 & 9 & 30 \\
TOTAL & 30 & 1 & 5 & 30 & 95 \\
\hline
\end{tabular}

Elaboración propia 


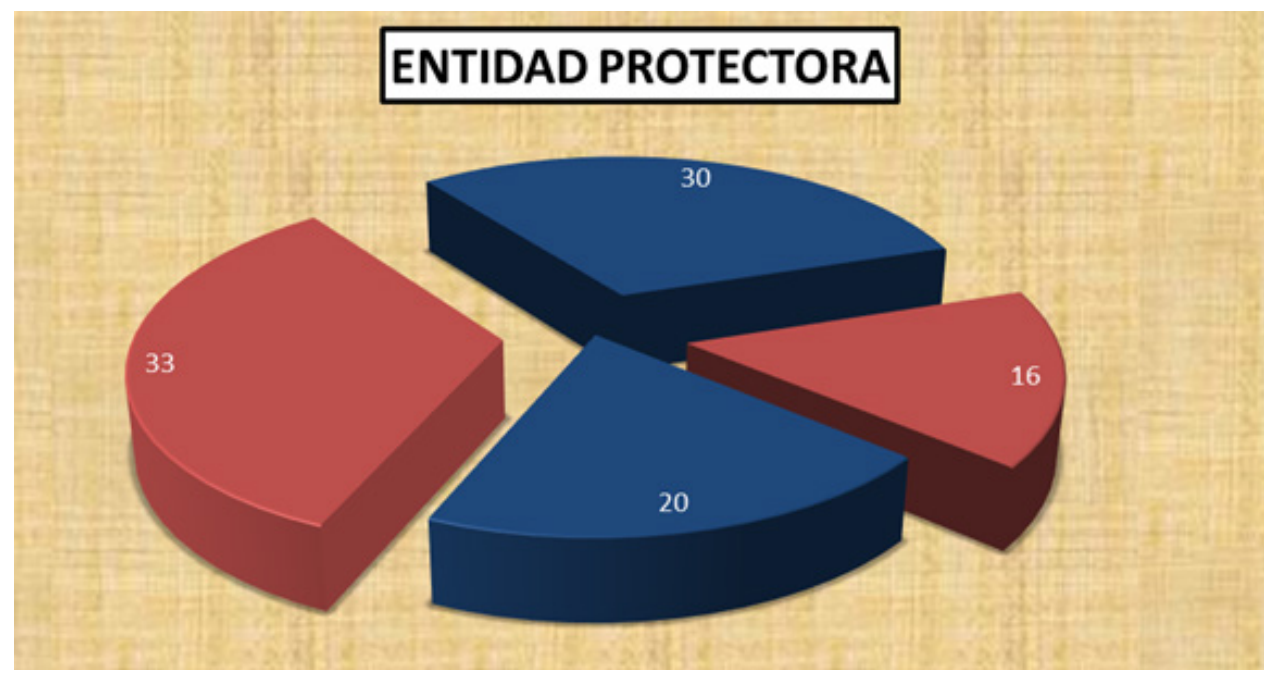

\section{Gráfico 5. Entidad Protectora}

Elaboración propia.

En la población de estudio seleccionada aleatoriamente se realizó la siguiente cuantificación: población femenina 15 en esta oportunidad contestaron afirmativamente a que entidad acudir 5 pacientes, es decir $16.66 \%, .10$ contestaron negativamente $34.6 \%$.

Seguidamente en la población masculina, 15 en total, 12 contestaron no saber a qué entidad acudir es decir el $40 \%$, en su defecto 3 pacientes contestaron afirmativamente es decir el 10\%.

6. ¿ iLe han informado sobre los riesgos y sus derechos al momento de realizarle un procedimiento médico?

SI $\mathrm{NO}$

Tabla 6

Riesgos Médicos

\begin{tabular}{cccccc}
\hline GÉNERO & POBLACIÓN & CONOCE & $\%$ & $\begin{array}{c}\text { NO } \\
\text { CONOCE }\end{array}$ & $\%$ \\
\hline FEMENINO & 15 & 5 & 16.6 & 10 & 33.3 \\
MASCULINO & 15 & 3 & 10 & 12 & 40 \\
TOTAL & 30 & 1 & 5 & 30 & 95 \\
\hline
\end{tabular}

Elaboración propia. 


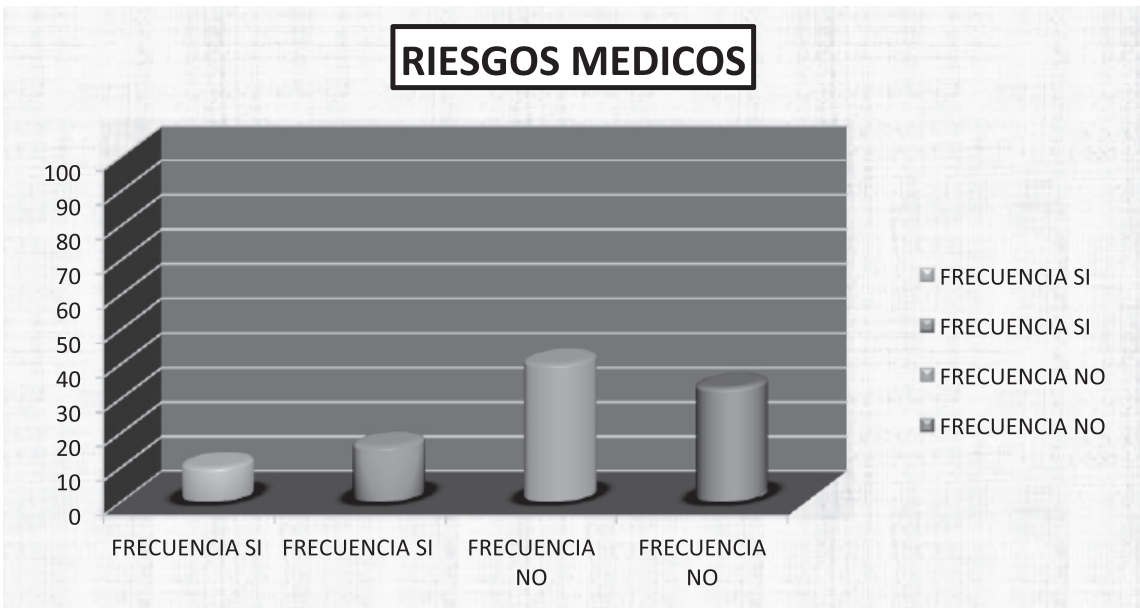

Gráfica 6. Riesgos Médicos

Elaboración propia.

Riesgos médicos: dentro del grupo aleatorio seleccionado en la investigación, la población total de 30 pacientes se cuantifico así: población masculina 15 , el $40 \%$ contesto negativamente, es decir, 12 pacientes que manifiestan no tener información oportuna sobre los riesgos médicos; y el 10\% contestó afirmativamente, es decir 3 pacientes.

Población femenina: 15, el 33\% contesto negativamente a la pregunta sobre el derecho a la información sobre riesgos médicos, es decir, 10 pacientes. En su defecto el 16.6\% contestó afirmativamente haber sido informado sobre riesgos médicos es decir 5.

7. ¿Ha conocido por parte de la Defensoría del Pueblo, información amplia como entidad Defensora del Paciente?

SI $\mathrm{NO}$

Tabla 7

Entidad defensora del paciente

\begin{tabular}{cccccc}
\hline GÉNERO & POBLACIÓN & CONOCE & $\%$ & $\begin{array}{c}\text { NO } \\
\text { CONOCE }\end{array}$ & $\%$ \\
\hline FEMENINO & 15 & 5 & 16.6 & 10 & 33.3 \\
MASCULINO & 15 & 3 & 10 & 12 & 40 \\
TOTAL & 30 & 1 & 5 & 30 & 95 \\
\hline
\end{tabular}

Elaboración propia. 

del servicio: estudio de caso hospital universitario de Sincelejo, año 2017

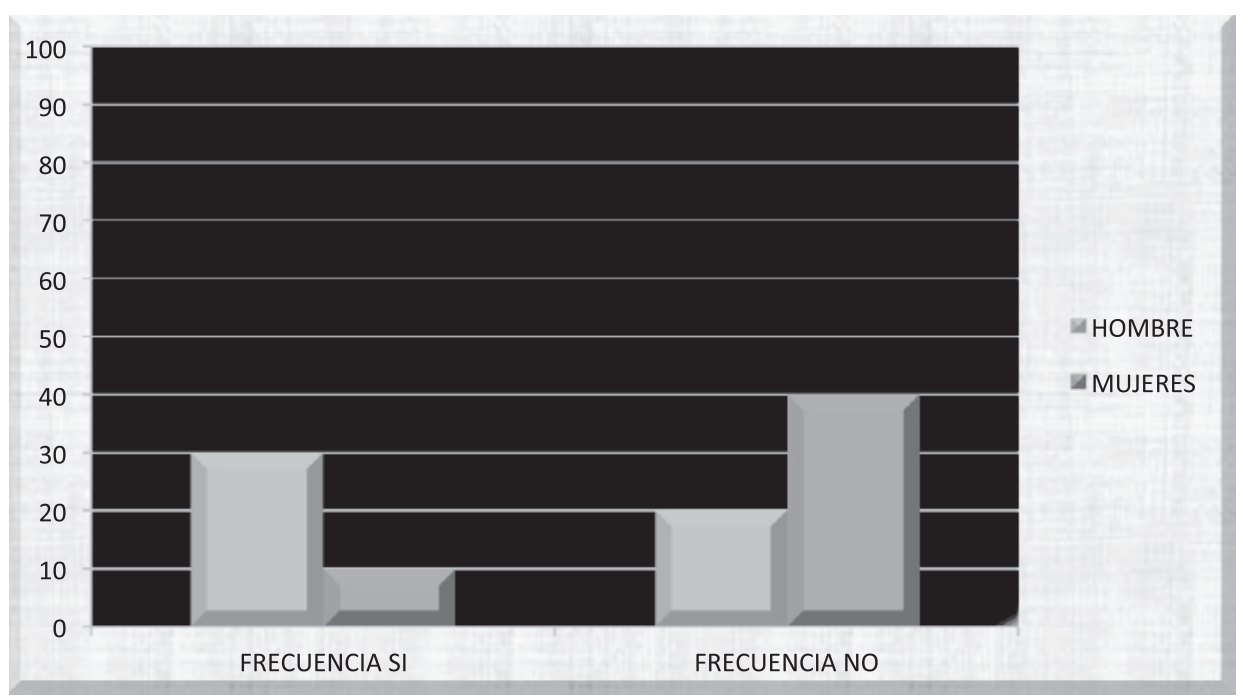

\section{Gráfico 7. Entidad defensora del paciente}

\section{Elaboración propia.}

Defensoría del pueblo. Dentro del grupo de pacientes que acuden al hospital universitario de Sincelejo seleccionamos aleatoriamente una población de 30 pacientes. A lo que respondieron a la pregunta y de manera cuantitativa señalamos así: población masculina: 15, a los que el 30\% respondieron negativamente es decir 9 pacientes no tienen información en cuanto al papel protector de la entidad, por el contrario el 20\% de la muestra tomada respondió afirmativamente respondió afirmativamente.

Población femenina. 15, respondieron negativamente a la pregunta de esta muestra el $40 \%$, es decir 12 pacientes en su defecto el 10\% respondió afirmativamente es decir 3 pacientes

\section{Conclusión}

Se ha logrado analizar que en relación a los mecanismos de información sobre las rutas de protección a los pacientes en caso de falla del servicio: estudio de caso hospital universitario de Sincelejo, año 2017 , los integrantes del Sistema de Salud en Colombia, refiriéndonos a las E.P.S e I.PS, y naturalmente, el personal médico se ha visto abocado a un sinnúmero de dificultades desde el orden administrativo, asistencial y económico que convergen jurídicamente con el derecho a la salud y mayormente con los derechos de los pacientes cuando en materia de responsabilidad médica 
se trata, en tanto que las fallas en la prestación de los servicios médicos aumentan y notablemente se encuentra el desconocimiento que los usuarios del servicio médico tienen respecto a sus derechos y las acciones jurídicas correspondientes a emprender frente a estos determinados casos. Denotándose en primera instancia la ausencia del Estado en información de las rutas de protección que como garante de sus connacionales adolecen las entidades supletorias de la regulación dichas garantías. En segunda instancia el legislativo colombiano es áulico y deshumaniza el servicio de salud, cuando de reojo observa que el sistema colapsa cada vez más por la ineficacia de las normas reglamentarias que pululan sin cesar, en tanto que la institucionalidad no resuelve el principio de dignidad vulnerado en salud. En tercera instancia en esta conclusión definimos que los medios de control regido por el derecho administrativo como la reparación directa en nuestro caso, es la tabla de salvación en la que hay que seguir instituyendo de cara a los daños y perjuicios que comúnmente las instituciones de salud pública en nuestro país vienen infringiendo, volviéndose indolentes con la economía del Estado y del paciente precisamente, por la falta de vigilancia de las entidades y la irresponsabilidad médica y del sistema en cuanto a la salud se refiere.

La responsabilidad medica merece especial atención en el contexto actual pues ha suscitado un interés férreo por parte de los abogados en virtud de las circunstancias que rodean al paciente o a sus familiares cuando han denotado fallas en la prestación del servicio, error médico, algún tipo de culpa médica, negligencia, impericia, imprudencia e inobservancia en el acto médico. Es por ello que a la luz del derecho, las demandas por responsabilidad médica son una situación actual, compleja y costosa, que concierne a los profesionales e instituciones de salud, a los pacientes y a sus allegados, a los legisladores, las autoridades judiciales entre otras. Son el eje principal del problema de la atención de la salud y la enfermedad: La seguridad del paciente amparada ésta en el sistema obligatorio de la garantía de la calidad en los servicios de salud con el Decreto ley 1011 de 2006.

\section{Referencias}

Acosta, M., y Delk, C. (s.f.). Responsabilidad Medica: elementos, naturaleza y carga de la prueba. Revista de Derecho Privado.

Arango Pérez, Juan Pablo, Avendaño Ayala Fabio, Martínez Quiñonez Iván. Demandas por Responsabilidad Médica Atendidas en el Centro De Estudios En Derecho Y Salud - CENDES- de la Univer- 
sidad CES. Medellín 2005 A 2009. Trabajo de Grado Para Optar al Título de Especialista en Valoración del Daño Corporal.

Barona R. (2016). Responsabilidad médica y hospitalaria. Editorial leyer. Bastidas, N. (2013). La mala práctica médica y los Derechos Humanos. Razón y Palabra, revista electrónica en América Latina, (81) Nov/2012-Ene/2013, s, p. 2.

Bueres, J., y Zaffaroni, E.,(s.f.). Responsabilidad Medica, Aspectos Civiles y Penales. Edit. Temis - Hammurabi- Pontificia Universidad Javeriana. Colección Internacional No 52

Código General del Proceso (2012). Ley 1564 de 2012. Comentado por Miguel Enrique Rojas Gómez, edit. Escuela de Actualización Jurídica, segunda edición,2013.

Código Sanitario Nacional (1991). Ley 42 de 1945: dispone la creación de la escuela superior de asuntos médico legales.

Código Sanitario Nacional (1952). Ley 9 de 1952. Recuperado de https:// www.disanejercito.mil.co/direccion_sanidad_ejercito_nacional/ institucional/prensa_comunicaciones/parametrizacion/2129398

Congreso de la Republica (2012). Ley 1564 de 2012. Código General del Proceso y se dictan otras disposiciones. Recuperado de http:// www.secretariasenado.gov.co/senado/ basedoc/ley_ 1564_2012. html

Congreso de la Republica (1993). Ley 100 de 1993: Sistema de seguridad social integral (SGSSS). Recuperado de https://docs.supersalud. gov.co/PortalWeb/Juridica/ Leyes/L0100_93.pdf

Fernández, M. (2014). La responsabilidad medica problemas actuales. Biblioteca de tesis doctorales, Editorial Ibáñez. p. 519, 521, 522, 523,525 .

Guzmán, F., Delgadillo, E., y Rodríguez, G. (s.f.). Responsabilidad Médica. Revista Sociedad Colombiana de Anestesiología y Reanimación - SCARE.

Guzmán, F. (s.f.), Norma Jurídica y Acto Jurídico. Documentos Originales, Revista Heraldo Medico.

Guzmán, F., Franco, E., Morales, M., y Mendoza, J. (1994). El Acto médico, implicaciones éticas y legales. Revista Acta Médica Colombiana, 19 (3) mayo-junio de 1994, comunicaciones y conceptos. http:// www.ces.edu.co/index.php/centros-de-servicio/cendes 
Jaramillo, C. (2016). Responsabilidad Civil Médica, la relación médico-paciente. Edit. Pontificia Universidad Javeriana Bogotá, colección de ensayos 2016, Segunda edición p. 60.

Koteich, M.(2012). La reparación del daño como mecanismo de tutela de la persona. Editorial universidad externado de Colombia. Bogotá Colombia.

López, J. (2014). La garantía de los derechos humanos del paciente a través del derecho Constitucional, procesal constitucional y el derecho de daños. Prolegómenos. Derechos y Valores, 17(34) julio-diciembre, 2014, pp. 53-77. Universidad Militar Nueva Granada, Bogotá, Colombia

Matera, J. (2018). Responsabilidad médica del estado. Editorial Librería Jurídica Sánchez R 1, edición, p.p. 15,53, 45.

Ministerio de Educación Nacional (MEN, 1962). Ley 14 de 1962. Normas relativas al ejercicio de la medicina. Recuperado de https://www. mineducacion.gov.co /1621/articles-103807_archivo_pdf.pdf

Ministerio de Educación Nacional (MEN, 1981). Ley 23 de 1981: Normas en Materia de Ética Médica. Recuperado de https://www.mineducacion.gov.co/1621/articles-103905_archivo_pdf.pdf

Ministerio de Salud y Protección Social (1990). Ley 10 de 1990: Por la cual se reorganiza el Sistema Nacional de Salud. Recuperado de https:// www.minsalud.gov.co/Normatividad_Nuevo/LEY\%200010\%20 DE\%201990.pdf

Ministerio de Salud y Protección Social (2006). Decreto 1022 de 2006: Sistema Obligatorio de Garantía de Calidad de la Atención de Salud del Sistema General de Seguridad Social en Salud. Recuperado de https://www.minsalud.gov.co/Normatividad_Nuevo /DECRETO\%201011\%20DE\%202006.pdf

Ministerio de Salud y Protección Social (2006). Ley 1122 de 2007: Sistema General de Seguridad Social en Salud. Recuperado de https://www. minsalud.gov.co/sites/rid/Lists/BibliotecaDigital/RIDE/DE/DIJ/ley1122-de-2007.pdf

Ministerio de Salud y Protección Social (2013). Resolución número 1441 de 2013: procedimientos y condiciones que deben cumplir los Prestadores de Servicios de Salud para habilitar los servicios. Recuperado de https://www.minsalud.gov.co/sites/rid/Lists/BibliotecaDigital/ RIDE/DE/DIJ/resolucion-1441-de-2013.pdf

Ministerio de Salud y Protección Social (2015). Ley 1751 estatutaria de 2015 SOGC: derechos y deberes de las personas en relación con el 
derecho fundamental a la salud. Recuperado de https://www.minsalud.gov.co/Normatividad_Nuevo/Ley\%201751 \%20de\% 202015. pdf

Obando, B. (2016). Bioderecho. Librería Jurídica Sánchez R. Ltda. Recuperado de https://lijursanchez.com/blog/bioderecho-con-santiago-obando/ p. 27,28,32

Solórzano, C. (2011). Derecho penal y responsabilidad Médica en Colombia. Ediciones nueva Jurídica, Univ. Católica, $1^{\text {a }}$ edición.

Restrepo, N. (2015). Tendencias de las demandas por responsabilidad médica radicadas en el Cendes entre 2010 y el 2014. Universidad CES. Medellín.

Rodríguez, L. (2015). Derecho Administrativo General y Colombiano. Editorial Temis decimonovena edición 2015, pág. 363.

Ruiz, W. (2004). La responsabilidad Médica en Colombia. Criterio Jurídico Santiago de Cali, 4, p. 197,200 ISSN 1657-3978.

Ruiz, W. (2004). La responsabilidad Médica en Colombia. Revista Criterio Jurídico Documental 4, p.p. 195-216.

Solano, J. (2016). Medios de Control Contencioso Administrativo. Ediciones Doctrina y Ley 2016, p.p. 30, 39, 144, 145

Torres, L. (2016). Ensayo responsabilidad administrativa por falla en la prestación del servicio de salud. Especialización en Derecho Administrativo, UMNG, p.p. 13-21.

Yepes, S. (2008). La responsabilidad Civil Médica. Biblioteca jurídica Dike edición 2008, p.p. 21, 36, 37, 43, 48, 49, 53, 55, 78,79.88,92. 